\title{
Geocronologia Rb-Sr e Características G eoquímicas dos Diques Máficos da Região de Nova Lacerda e Conquista D'O este (MT), Porção Sudoeste do Craton Amazônico
}

\author{
$\mathrm{Rb}-\mathrm{Sr} \mathrm{G}$ eochronology and G eochemical Characteristics of Mafic Dikes in the Nova \\ Lacerda and Conquista D'O este Region, Mato Grosso, SW Amazonian Craton
}

Paulo César Corrêa da Costa ${ }^{1,4}$ (pccorrea@ufmt.br), Vicente Antonio Vitório Girardi² (girardi@ usp.br), João Batista de Matos'1,4 (jmatos@cpd.ufmt.br), Amarildo Salina Ruiz 3 (asruiz@ rc.unesp.br)

${ }^{1}$ Departamento de Recursos Minerais - Instituto de Ciências Exatas e da Terra - UFMT Av. Fernando Corrêa da Costa s/n, CEP 78060-900, Cuiabá, MT, BR

${ }^{2}$ Departamento de Mineralogia e G eotectônica - Instituto de Geociências - USP, São Paulo, SP, BR ${ }^{3}$ Departamento de G eologia Geral - Instituto de Ciências Exatas e da Terra - UFMT, Cuiabá, MT, BR ${ }^{4} \mathrm{G}$ rupo de Pesquisas em Evolução Crustal e Metalogenia GUAPO RÉ, Cuiabá, MT, BR

Recebido em 07 de agosto de 2008; aceito em 30 de outubro de 2008

\section{RESUMO}

Diques máficos NNW da região de Nova Lacerda e Conquista D’Oeste, em Mato Grosso, intrudem o Granito Nova Lacerda (1462 $\pm 12 \mathrm{Ma}$ ) pertencente ao Domínio Jauru da Província Rondoniana-San Ignacio (1,55 - 1,3 Ga), na parte SW do Craton Amazônico. São representados por diabásios, metadiabásios e anfibolitos. Os metadiabásios são produtos da uralitização dos diabásios. Tais rochas possuem afinidade toleítica e composição predominantemente basáltica, com ligeira variação para andesito-basáltica. Datações $\mathrm{Rb}-\mathrm{Sr}$ indicaram idades de $1380 \pm 32 \mathrm{Ma}$ para os diabásios e de $1330 \pm 120 \mathrm{Ma}$ para os metadiabásios. Dados geoquímicos indicam que a variação composicional de diabásios e metadiabásios decorre de cristalização fracionada a partir de magmas toleíticos evoluídos. A origem dos magmas basálticos deve estar relacionada a uma fonte mantélica heterogênea.

Palavras-chave: diques máficos, geoquímica, geocronologia, Craton Amazônico.

\begin{abstract}
In the Nova Lacerda and Conquista D’Oeste regions, Mato Grosso State, SW part of the Amazonian Craton, mafic dikes trending NNW intrude the Nova Lacerda Granite (1462 $\pm 12 \mathrm{Ma}$ ), within the Jauru Domain, in the Rondonia-San Ignacio Province (1.55 - $1.3 \mathrm{Ga}$ ). The mafic swarm comprises diabases, metadiabases and amphibolites. Metadiabases originated from uralitization of diabases. These rocks have tholeiitic affinity and predominant basaltic composition. Some samples are andesi-basalts. The ages of diabases and metabasites are $1380 \pm 32 \mathrm{Ma}$ and $1330 \pm 120$ Ma respectively. Geochemical data indicate that the compositional variation of diabases and metadiadases is due to fractional crystallization of evolved tholeiitic magmas. The origin of the basaltic magmas is related to a heterogeneous mantle source.
\end{abstract}

Keywords: mafic dikes, geochemistry, geochronology, Amazonian Craton. 


\section{INTRODUÇÃO}

Enxames de diques máficos são armas poderosas para estudos referentes à composição do manto superior e na análise de estudos tectônicos regionais. Na Plataforma Sul-Americana tais pesquisas, principalmente as voltadas para o estudo de diques e intrusivas básicas Meso e Paleoproterozoicos têm propiciado a elaboração de vários trabalhos nas diversas regiões cratônicas existentes, ou seja, no Craton do São Francisco (Bellieni et al., 1991, 1995, 1998; Bastos Leal et al., 1994; Menezes Leal et al., 1995; Pinese, 1997; Moraes Brito et al., 1989; Mazzucchelli et al., 2001; D'Agrella et al., 2004; Corrêa da Costa et al., 2006); no Bloco Arqueano Crixás - Goiás (Corrêa da Costa e Girardi, 2004, 2005; Corrêa da Costa et al., 2006a); no Craton do Rio de La Plata (Bossi et al., 1993; Rivalenti et al., 1995; Mazzucchelli et al., 1995; Girardi et al., 1996; Teixeira et al., 1999) e no Craton Amazônico (Rivalenti et al., 1998; Menezes Leal et al., 2006; Teixeira et al., 2006; Girardi et al., 2008). Os trabalhos citados constituem exemplos de estudos de enxames individuais, porém trabalhos tentando estudar comparativamente tais intrusões, visando principalmente comparar fontes mantélicas e implicações tectônicas também têm sido realizados (Iacumin et al., 2001, 2003; Girardi, 2006).

O enxame de diques de Nova Lacerda e Conquista D'Oeste - MT foram objetos de alguns poucos trabalhos em simpósios e congressos (e.g., Corrêa da Costa et al., 2005; Ruiz et al., 2005), que constituem informações pioneiras sobre esses corpos na região SW do Craton Amazônico no Estado do Mato Grosso. O presente trabalho é o resultado de dados geoquímicos e datações isotópicas $\mathrm{Rb}-\mathrm{Sr}$ em rocha total desse enxame nessa região. Deste modo, os resultados obtidos neste trabalho constituem uma contribuição para situar melhor a época em que ocorreram os processos de intrusão desses corpos, assim como caracterizá-los petrográfica e geoquimicamente de molde a dar início a estudos sobre sua fonte mantélica e processos petrogenéticos.

\section{CONTEXTO GEOLÓGICO}

Segundo o modelo clássico tectônico (Tassinari e Macambira 1999, 2004; Teixeira et al., 1989; Tassinari et al., 2000), o Craton Amazônico é formado por um núcleo central Arqueano e por províncias geocronológicas Paleo e Mesoproterozoicas sucessivamente mais jovens que se agregaram através de acreção de arcos magmáticos. Cordani e Teixeira (2007) efetuaram uma revisão dos conhecimentos reafirmando o modelo acrecionário. De acordo com esses trabalhos a Província Amazônica Central (ca $>2,6 \mathrm{Ga})$ constitui o núcleo Arqueano e as províncias Maroni-Itacaiunas (2,25 - 2,05 Ga), Ventuari-Tapa- jós (1,95 - 1,81 Ga), Rio Negro-Juruena (1,78 - 1,55 Ga), Rondoniana-San Ignácio (1,55 - 1,3 Ga) e Sunsás-Aguapeí (1,25 - 1,0 Ga) são produtos de sucessivos eventos de colisão-acreção, guiados por subducções. Esse modelo evolutivo no Estado do Mato Grosso encontrou suporte através do trabalho de Geraldes et al. (2001), fundamentado em grande acervo de dados isotópicos e que relacionou sucessivos eventos plutônicos Paleo e Mesoproterozoicos a ambientes de arco de ilhas.

Os diques máficos em questão situam-se na Província Rondoniana-San Ignacio. Sua principal característica relaciona-se à presença de orógenos colisionais e cinturões juvenis acrecionários subordinados. Compreende três grandes ciclos orogênicos (1,51 - 1,48; 1,44 - 1,42; e 1,36 - 1,32 Ga) (Teixeira et al., 2006, Girardi et al., 2008). A diversidade litológica é muito grande e relacionada a várias unidades geológicas regionais, incluindo rochas magmáticas félsicas cálcio-alcalinas, associações mangerito-charnockito-granito, rochas máficas e ultramáficas ígneas e metamórficas, metassedimentos e gnaisses. Várias bacias de rifteamento e do tipo aulacogênico são contemporâneas ao orógeno Sunsás, responsável também por reativações (ver Tabela 1, em Teixeira et al., 2006 para detalhes).

Com o avanço dos mapeamentos geológicos o emprego do conceito de terrenos passou a ser amplamente utilizado na região sudoeste do Craton Amazônico, com a finalidade de detalhar os processos envolvidos na interação das províncias geocronológicas. Saes (1999) apresenta um arranjo tectônico, onde se destacam de oeste para leste os seguintes terrenos: Paraguá, Rio Alegre, Santa Helena e Jauru. Ruiz (2005) através de dados de campo, geoquímicos e geocronológicos (U-Pb, Ar-Ar e Sm-Nd), sugeriu para o sudoeste do Craton Amazônico, compartimentação em Domínios Tectônicos a saber: Cachoeirinha, Jauru, Rio Alegre, Santa Bárbara, Paragua e Sunsás. A área de estudo situa-se no Domínio Jauru (Figura 1).

O Domínio Tectônico Jauru é constituído por um complexo metavulcânico-sedimentar, por uma suíte intrusiva máfica-ultramáfica, e suítes e batólitos intrusivos graníticos e gnáissicos de composição variada (sienogranítica, granítica, tonalítica, granodiorítica e monzogranítica). Tais unidades estão sotopostas ao Grupo Aguapeí, formado por rochas metassedimentares. Datações U-Pb mostram idades no intervalo 1419 - 1586 Ma para os zircões das rochas graníticas e gnáissicas, e de 1230 Ma para os zircões detríticos do Grupo Aguapeí. A Tabela 1 resume a subdivisão e características das unidades desse domínio de acordo com Ruiz (2005).

Na região estudada, próxima a Nova Lacerda e Conquista D'Oeste, os diques máficos cortam três unidades do Domínio Jauru. A grande maioria deles corta rochas pertencentes à Suíte Intrusiva Pindaituba (Figura 2), que en- 
Tabela 1. As principais unidades geológicas e os eventos termo-tectônicos do Domínio Jauru (modificado de Ruiz 2005).

\begin{tabular}{|c|c|c|c|c|}
\hline Unidades estratigráficas & Descrições res umidas & Idades U-Pb (Ma) & $\mathrm{T}_{\mathrm{DM}}(\mathrm{Ga})$ & $\boldsymbol{\varepsilon}_{\mathrm{Nd}(\mathrm{t})}$ \\
\hline Grupo Aguapeí & Rochas metassedimentares & 1230 & - & - \\
\hline $\begin{array}{l}\text { Suíte Intrusiva } \\
\text { Pindaituba }\end{array}$ & $\begin{array}{l}\text { Granitóides foliados (biotita hornblenda granitos, } \\
\text { granodioritos, sienogranitos e tonalitos) }\end{array}$ & $\begin{array}{c}1426 \pm 27 \\
a \\
1465 \pm 12\end{array}$ & 1,5 a 1,9 & 1,18 a 4 \\
\hline $\begin{array}{l}\text { Suíte Intrusiva } \\
\text { Santa Helena }\end{array}$ & Gnaisse monzogranitíco a tonalítico & $\begin{array}{c}1419 \text { a } 1456 \\
1481 \pm 07\end{array}$ & 1,5 a 1,6 & - \\
\hline Batólito Água Clara & Gnaisse granodiorítico & $1468 \pm 35$ & - & - \\
\hline $\begin{array}{l}\text { Suíte Intrusiva } \\
\text { Rio Novo }\end{array}$ & Ortognaisses tonalíticos a monzograníticos & $\begin{array}{c}1552 \pm 03 \\
1586 \pm 31 \\
1568 \pm 43\end{array}$ & 1,8 a 1,9 & 0 a 2,5 \\
\hline Suíte Córrego Dourado & $\begin{array}{c}\text { Rochas plutônicas máficas e ultramáfica } \\
\text { (metagabros e serpentinitos) }\end{array}$ & - & - & - \\
\hline $\begin{array}{l}\text { Complexo Metavulcano- } \\
\text { sedimentar Rio Galera }\end{array}$ & $\begin{array}{l}\text { Anfibolitos, muscovita xistos, silimanita xistos, } \\
\text { gnaisses, metacherts }\end{array}$ & - & 1,8 & 3,68 \\
\hline
\end{tabular}

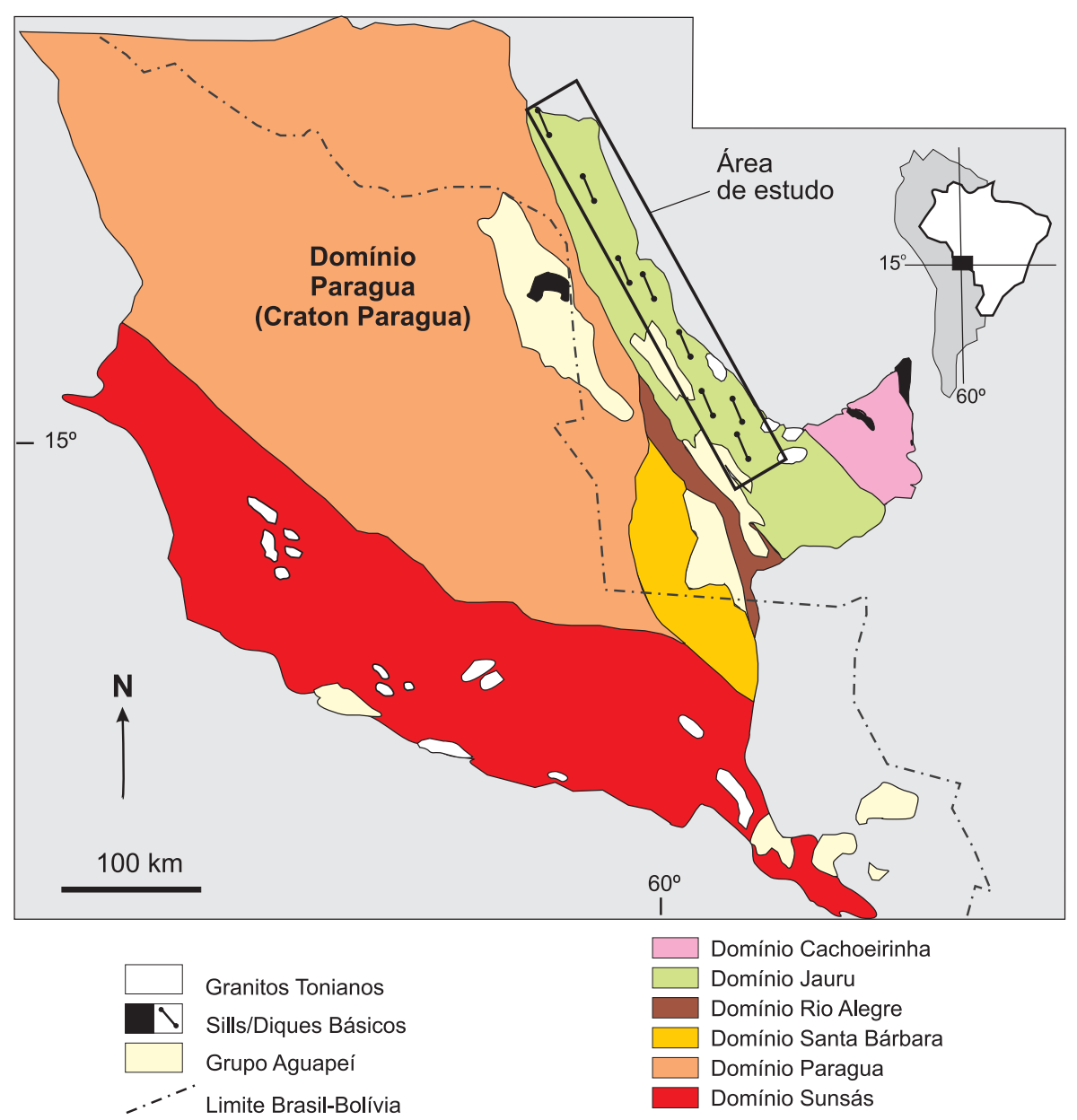

Figura 1. Esboço dos Domínios Tectônicos do sudoeste do Craton Amazônico (modificado de Ruiz et al., 2005). 


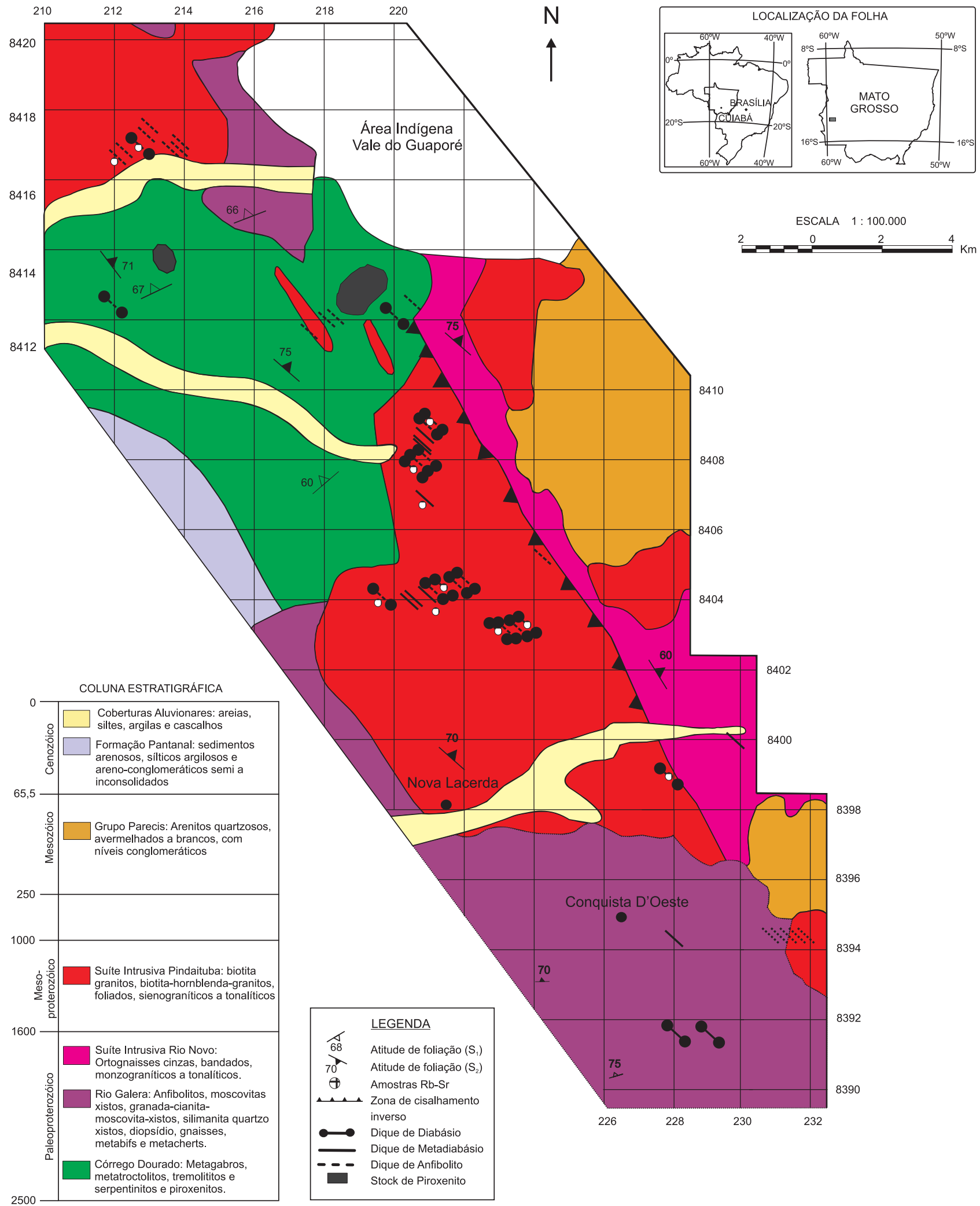

Figura 2. Mapa geológico da região investigada (modificado de Felipe, 2007). 
globa biotita granitos, biotita-hornblenda granitos sienogranitos e tonalitos. Raros diques intrudem rochas da Suíte Rio Galera composta por anfibolitos, moscovita-xistos, granada-cianita-moscovita xistos, sillimanita-quartzo xistos, diopsiditos, gnaisses metacherts e metabifs; e da Suíte Córrego Dourado, formada por metagabros, metatroctolitos, tremolititos, piroxenitos e serpentinitos. Os diques estudados no presente trabalho intrudem o Granito Nova Lacerda, cuja idade U-Pb é de $1462 \pm 12 \mathrm{Ma}$ (Ruiz, 2005), pertencente à Suíte Intrusiva Pindaituba. Trata-se de corpo orientado regionalmente na direção NNW, considerado tardicinemático por exibir estrutura maciça nas suas porções internas e foliação nas bordas (e.g., Ruiz, 2005; Felipe, 2007). O Granito Nova Lacerda possui cor cinza clara, é leucocrático, fanerítico, inequigranular e de estrutura maciça. Apresenta textura porfiroclástica, granulação média a grossa, e é constituído por quartzo, oligoclásio, microclínio, biotita e anfibólio. Titanita, allanita, apatita, zircão e opacos são acessórios, e sericita, moscovita e epidoto, minerais de alteração.

\section{Diques Máficos}

Os diques máficos apresentam direção $\mathrm{N} 30^{\circ}-40^{\circ} \mathrm{W}$, com aproximadamente $150 \mathrm{~km}$ de extensão e são recobertos pelos sedimentos do Grupo Parecis, na porção nordeste da área (Figura 2). Suas espessuras variam entre $50 \mathrm{~cm}$ e $30 \mathrm{~m}$, predominando os diques de $3 \mathrm{~m}$ de espessura. Ruiz et al. (2005) discutiram a importância dos enxames de diques máficos na atividade magmática ocorrida no sudoeste do Craton Amazônico. Corrêa da Costa et al. (2005) caracterizaram os diques e litotipos máficos-ultramáficos de Nova Lacerda e Conquista D’Oeste através de análise petrográfica e geoquímica, dividindo-os em diabásios, metadiabásios e anfibolitos.

Os diabásios são rochas faneríticas de cor escura, granulação variando entre fina a predominantemente média. Apresentam texturas intergranular, subofítica e ofítica. Os constituintes mineralógicos essenciais são plagioclásio, augita, e enstatita em menor proporção, que juntos correspondem a aproximadamente $80-90 \%$ do volume total da amostra. Como minerais acessórios observam-se anfibólio primário, quartzo, apatita, biotita, titanita, epidoto e opacos.

Os metadiabásios são representados por rochas faneríticas de granulação média; têm texturas intergranular, subofíticas a ofíticas e são constituídos por plagioclásio, augita e anfibólio, produto da uralitização de piroxênio. Os minerais acessórios são quartzo, apatita, biotita, titanita, epidoto e opacos. Os metadiabásios preservam similaridades mineralógicas com os diabásios, diferindo apenas pela ausência dos intercrescimentos granofíricos e pela presença de uralitização. A uralitização ocorre como resultado de um hidrotermalismo dos estágios finais de cristalização das rochas deste grupo, preservando as texturas ígneas originais.

Os anfibolitos apresentam foliação proeminente (N40W) paralela à direção de intrusão de N30 - 40W e cor variando entre cinza esverdeado a cinza escuro. São rochas faneríticas, melanocráticas e de granulação variando de fina a média. Apresentam texturas nematoblásticas a granoblásticas e são constituídas por anfibólio (predominantemente hornblenda), plagioclásio, quartzo e diopsídio e como acessórios tem-se biotita, apatita, zircão, titanita, epidoto e opacos.

\section{MÉTODOS ANALÍTICOS}

As determinações $\mathrm{Rb}$-Sr em rocha total foram realizadas no Centro de Pesquisas Geocronológicas (CPGeo) do IGc/USP. As análises foram preparadas pelo método padrão de acordo com os procedimentos analíticos descritos por Kawashita (1972) e modificado por Sato et al. (1995). Foram realizadas 8 análises em diabásios e metadiabásios e 3 no Granito Nova Lacerda, pelo método de diluição isotópica para a determinação dos conteúdos de $\mathrm{Rb}, \mathrm{Sr}$ e das razões de ${ }^{87} \mathrm{Sr} /{ }^{86} \mathrm{Sr}$ (Tabela 2). As amostras, inicialmente pulverizadas, foram submetidas a uma dosagem prévia dos elementos $\mathrm{Rb}$ e $\mathrm{Sr}$ através de fluorescência de raios $\mathrm{X}$. Em função dos valores obtidos, foram selecionadas as amostras mais favoráveis, levando-se em conta a razão $\mathrm{Rb} / \mathrm{Sr}$ total e a distribuição dos pontos analíticos nos diagramas isocrônicos. As medidas da composição isotópica de estrôncio foram feitas em espectrômetro de massa VG-354 termoiônico dotado de multicoletor com amplificador Daly e sistema automático. As idades foram calculadas usando a constante de decaimento estabelecida por Steiger e Jaeger (1978), para $\lambda \mathrm{Rb}=1,42 \times 10^{-11} \mathrm{ano}^{-1}$. Os dados isotópicos foram tratados com o auxílio do programa Isoplot versão 2.10 de Ludwig (1999), e nas isócronas, o cálculo das idades foi baseado no Modelo $1(1 \sigma)$ do programa Isoplot.

A caracterização litogeoquímica foi realizada a partir da análise de trinta e uma amostras de rochas consideradas como as mais representativas dos diques máficos. As amostras selecionadas para as análises geoquímicas foram preparadas e analisadas no Laboratório do Departamento de Mineralogia e Geotectônica (GMG) do Instituto de Geociências (IGc) da Universidade de São Paulo. As análises químicas para determinação de elementos maiores e traços foram realizadas por fluorescência de raios $\mathrm{X}$, de acordo com método descrito por Mori et al. (1999). Os limites de detecção são 1 - 10 ppm e a precisão é maior que $2 \%$ para os elementos maiores, e entre 5 a $10 \%$ para os elementos traços. $\mathrm{O} \mathrm{Fe}_{2} \mathrm{O}_{3} \mathrm{~T}$ foi determinado pela análise quí- 
Tabela 2. Dados analíticos Rb-Sr dos diques. Dados obtidos por diluição isotópica.

\begin{tabular}{|c|c|c|c|c|c|c|}
\hline \multicolumn{7}{|c|}{ Diques de Diabásios } \\
\hline $\mathbf{N}^{\circ}$ lab./amostra & $\mathbf{R b}$ & $\mathrm{Sr}$ & ${ }^{87} \mathrm{Rb} /{ }^{86} \mathrm{Sr}$ & Erro & ${ }^{87} \mathrm{Sr} /{ }^{86} \mathrm{Sr}$ & Erro \\
\hline $4326 / \mathrm{NL}-14$ & 15,79 & 298,08 & 0,1533 & 0,0012 & 0,70583 & 0,00001 \\
\hline 4328/NL-34 & 7,38 & 261,19 & 0,0817 & 0,0006 & 0,70447 & 0,00002 \\
\hline $4325 / \mathrm{NL}-52$ & 23,18 & 276,03 & 0,2430 & 0,0019 & 0,70768 & 0,00001 \\
\hline $4331 / \mathrm{NL}-53$ & 20,31 & 275,90 & 0,2130 & 0,0017 & 0,70706 & 0,00003 \\
\hline \multicolumn{7}{|c|}{ Diques de Metadiabásios } \\
\hline $\mathbf{N}^{\circ}$ lab./amostra & $\mathbf{R b}$ & $\mathrm{Sr}$ & ${ }^{87} \mathrm{Rb} /{ }^{86} \mathrm{Sr}$ & Erro & ${ }^{87} \mathrm{Sr} /{ }^{86} \mathrm{Sr}$ & Erro \\
\hline $4324 / N L-1 A$ & 15,73 & 252,78 & 0,1800 & 0,0014 & 0,70611 & 0,00001 \\
\hline $4330 / \mathrm{NL}-12$ & 14,32 & 244,10 & 0,1698 & 0,0013 & 0,70585 & 0,00003 \\
\hline $4327 / \mathrm{NL}-76$ & 7,90 & 272,58 & 0,0839 & 0,0009 & 0,70433 & 0,00004 \\
\hline $4332 / \mathrm{NL}-78$ & 25,82 & 247,15 & 0,3024 & 0,0024 & 0,70848 & 0,00001 \\
\hline \multicolumn{7}{|c|}{ Granito Nova Lacerda (Encaixante) } \\
\hline $\mathbf{N}^{\circ}$ lab./amostra & $\mathbf{R b}$ & $\mathrm{Sr}$ & ${ }^{87} \mathrm{Rb} /{ }^{86} \mathrm{Sr}$ & Erro & ${ }^{87} \mathrm{Sr} /{ }^{86} \mathrm{Sr}$ & Erro \\
\hline $5220 / \mathrm{NL}-03$ & 62,80 & 472 & 0,385 & 0,000001 & 0,710897 & 0,000022 \\
\hline $5221 / \mathrm{NL}-49 \mathrm{~B}$ & 52,80 & 440 & 0,347 & 0,000001 & 0,710926 & 0,000020 \\
\hline $5222 / \mathrm{NL}-104$ & 294 & 118 & 7,300 & 0,000001 & 0,832636 & 0,000060 \\
\hline
\end{tabular}

mica como ferro total e o $\mathrm{FeO}$ foi calculado assumindo a razão $\mathrm{Fe}_{2} \mathrm{O}_{3} / \mathrm{FeO}=0,15$. Doze amostras foram selecionadas para análises de elementos terras raras e elementos traços por ICP-MS. A metodologia empregada é descrita por Navarro et al. (2008). A precisão é da ordem de 0,5 - 2\%. Os resultados estão apresentados na Tabela 3.

\section{GEOCRONOLOGIA Rb-Sr}

No tratamento dos dados geocronológicos e geoquímicos foram utilizados apenas os diabásios e metadiabásios. Devido às possíveis modificações químicas causadas pelo metamorfismo, os anfibolitos não são discutidos neste trabalho. A petrologia e geoquímica dos anfibolitos são apresentadas em Corrêa da Costa et al. (2005).

As determinações $\mathrm{Rb}-\mathrm{Sr}$ em rocha total foram realizadas em 8 amostras dos diques máficos, sendo 4 análises de diabásio e 4 de metadiabásio (Tabela 2). Para os diabásios foi obtida uma isócrona com idade de $1380 \pm 32 \mathrm{Ma}(1 \sigma)$, e razão ${ }^{87} \mathrm{Sr} /{ }^{86} \mathrm{Sr}$ inicial de $0,702838 \pm 0,000067$ e MSWD (mean square of weighted deviates) igual a 1,7 (Figura 3). O diagrama da Figura 4 mostra isócrona para os diques de metadiabásios com idade de $1330 \pm 120 \mathrm{Ma}(1 \sigma)$, e uma razão ${ }^{87} \mathrm{Sr} /{ }^{86} \mathrm{Sr}$ inicial de $0,70268 \pm 0,00034$ e MSWD igual a 2,2. Apesar do erro grande, esta idade assemelha-se à obtida para as amostras de diabásio. Os baixos valores de ${ }^{87} \mathrm{Sr} /{ }^{86} \mathrm{Sr}$ tanto de diabásios como de metadiabásios (Tabela 2), não sugerem influência importante de contaminação crustal na composição geoquímica e isotópica dos diabásios e metadiabásios.

O granito Nova Lacerda que é a rocha encaixante dos diques máficos, não forneceu uma isócrona $\mathrm{Rb}-\mathrm{Sr}$. No entanto, os valores de suas amostras quando lançados em diagrama isocrônico, embora não perfeitamente alinhados, mostram-se próximas de uma isócrona de referência de $1464 \pm 12 \mathrm{Ma}$ (idade U-Pb, Ruiz, 2005) indicando o limite máximo para a idade dos diques.

O conjunto de dados isotópicos apresentados mostram que os diques de diabásio e metadiabásio da região de Nova Lacerda e Conquista D’Oeste - MT foram formados durante o Mesoproterozoico (Ectasiano). Esta idade é próxima dos valores obtidos para as rochas da sequência Colorado em Rondônia, também pertencente à província Rondonian-San Ignacio, cuja idade média de 1,35 Ga (e.g., Girardi et al., 2005; Teixeira et al., 2006).

\section{GEOQUÍMICA DE ROCHA TOTAL}

Para avaliar a possibilidade de mobilização de elementos químicos dos litotipos máficos estudados foi utilizado os diagramas das razões de proporções moleculares (MPR) conforme proposto por Pearce (1968) e posteriormente por Beswick (1982) entre outros. Nos testes realizados através dos diagramas MPR, pode-se observar que, para os elementos utilizados, a tendência geral destas rochas (diabásio e metadiabásio) é retilínea e com pouca dispersão. Tais re- 
sultados, aliados aos diagramas que relacionam mg\# com elementos maiores e menores, a serem discutidos adiante, indicam que as rochas não sofreram mobilizações significativas dos elementos considerados e que as análises químicas apresentadas refletem composições originais.

Os diabásios e metadiabásios possuem afinidades toleíticas (Figura 5) e composição basáltica com uma ligeira variação composicional para basaltos andesíticos (Figura 6).

Os valores do índice de magnésio (mg\#) para as rochas estudadas apresentam variações entre 0,22 e 0,38 (Figuras 7 e 8 ) indicando tratar-se de magmas basálticos evoluídos. Magmas basálticos primários derivados da fusão parcial de peri-

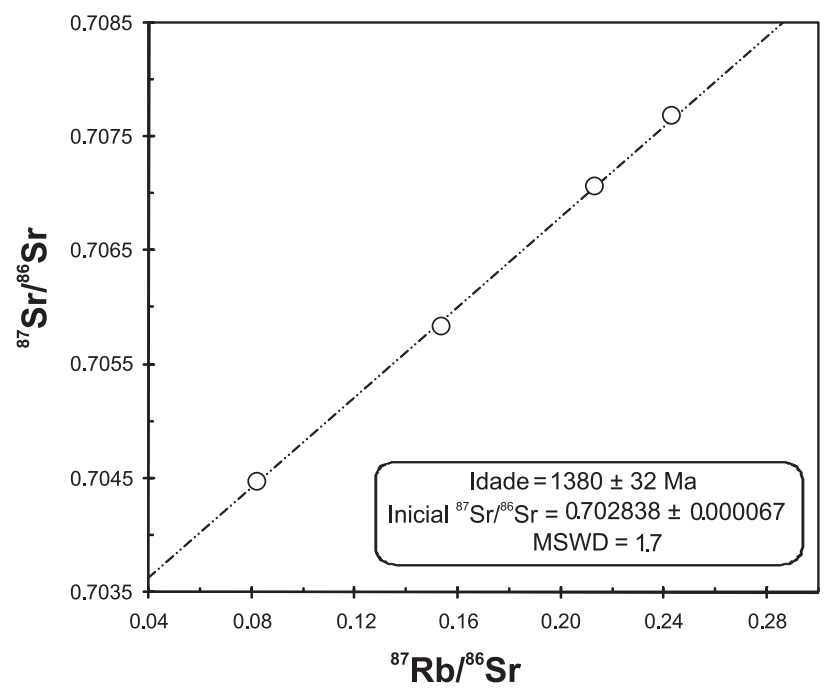

Figura 3. Diagrama isocrônico $\mathrm{Rb}-\mathrm{Sr}$ representativo dos diques de diabásios.

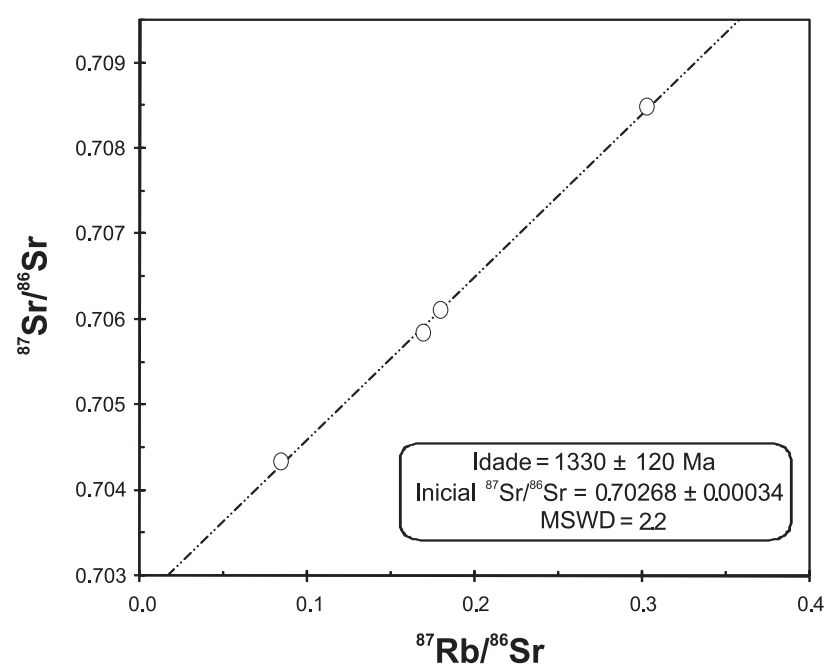

Figura 4. Diagrama isocrônico $\mathrm{Rb}$-Sr representativo dos diques de metadiabásios. dotitos mantélicos teriam valores de mg\# entre 0,74 e 0,80 (Jaques e Green, 1979, 1980; Takahashi e Kushiro, 1983).

Nas Figuras 7 e 8 observa-se que com a evolução magmática, ou seja, com a diminuição do número de magnésio (mg\#) ocorre um aumento nos teores de $\mathrm{TiO}_{2}, \mathrm{FeOT}, \mathrm{MnO}$, $\mathrm{K}_{2} \mathrm{O}, \mathrm{Na}_{2} \mathrm{O}, \mathrm{Ba}, \mathrm{Sr}, \mathrm{Zr}, \mathrm{Zn}$ e La, enquanto que, $\mathrm{Al}_{2} \mathrm{O}_{3}, \mathrm{SiO}_{2}$,

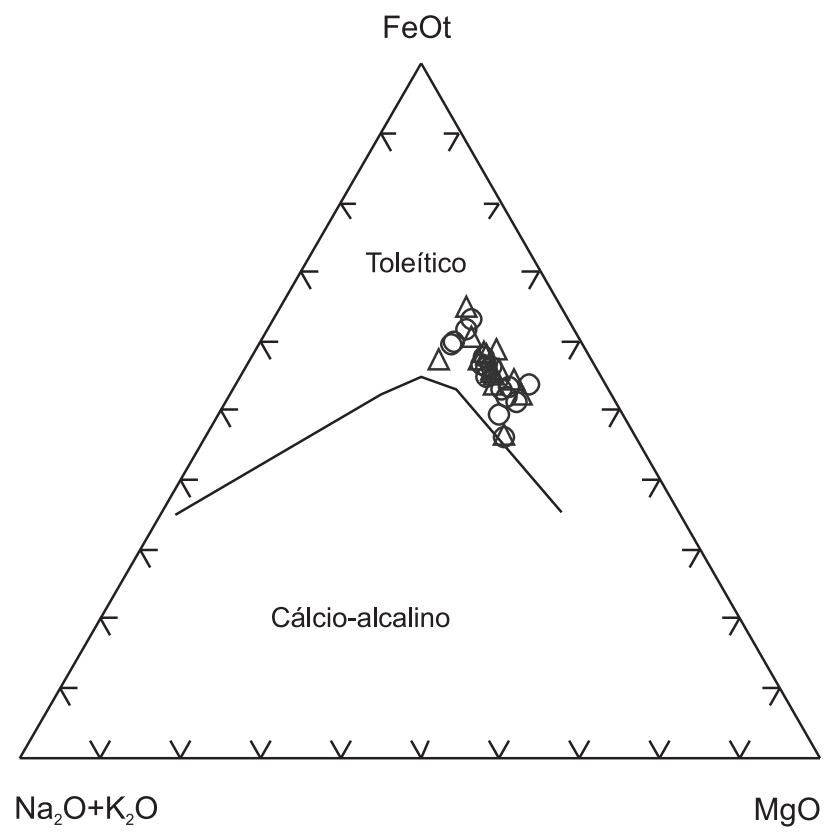

Figura 5. Diagrama AFM $\left(\mathrm{Na}_{2} \mathrm{O}+\mathrm{K}_{2} \mathrm{O}\right)-\mathrm{FeO}$ t-MgO para classificação geral dos litotipos máficos-ultramáficos, segundo Irvine e Baragar (1971). Símbolos: círculos = diabásios; triângulos = metadiabásios.

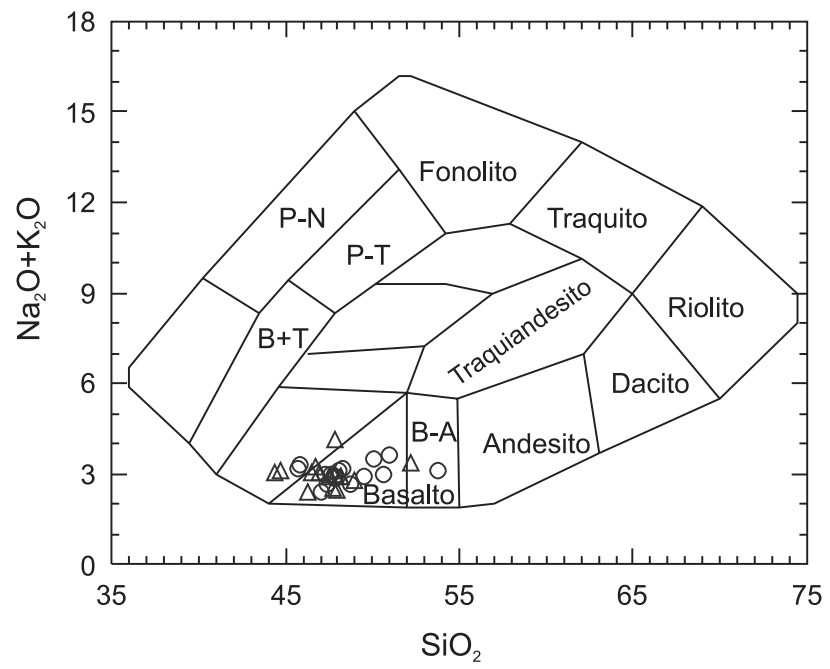

Figura 6. Diagrama de classificação geral dos litotipos máficos, segundo Cox et al. (1979). Símbolos como na Figura 5. 


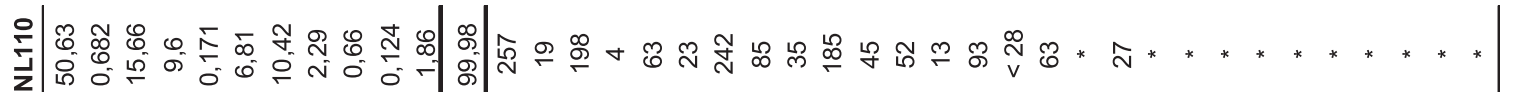

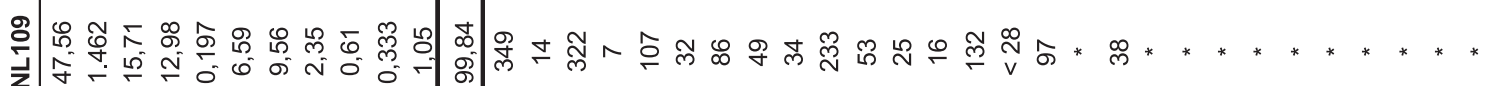

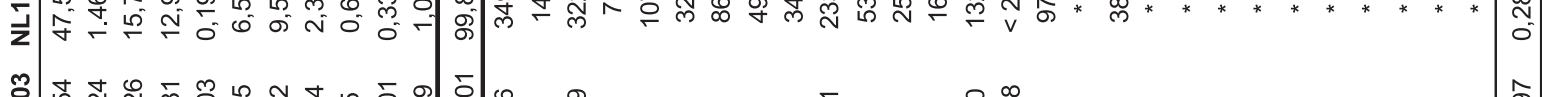

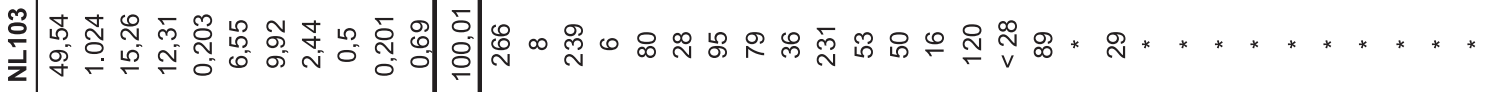

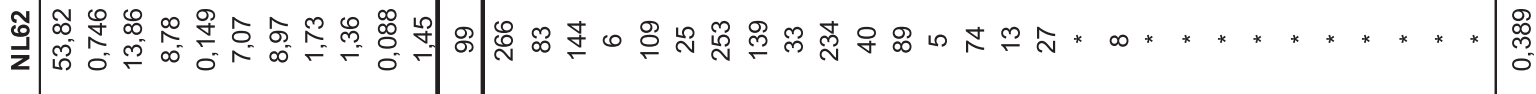

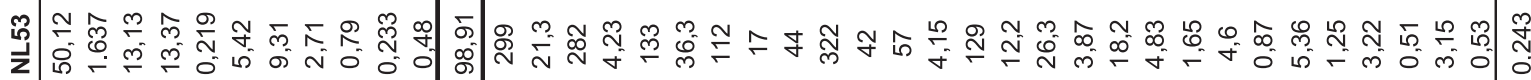
กิ

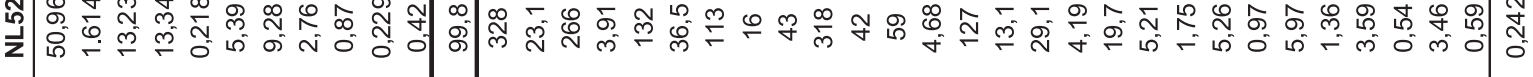

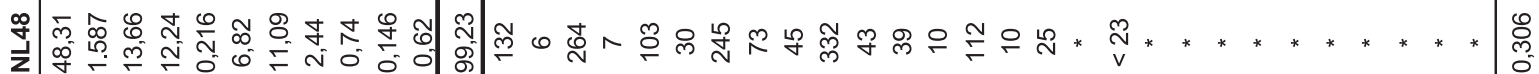

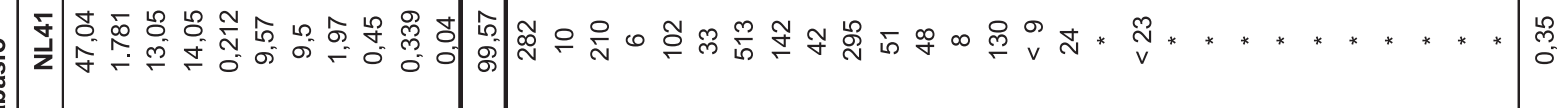

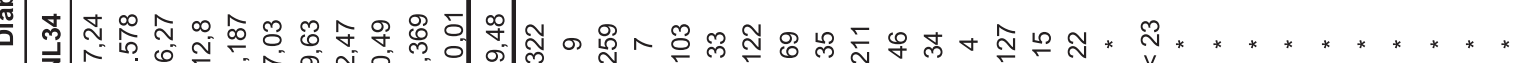

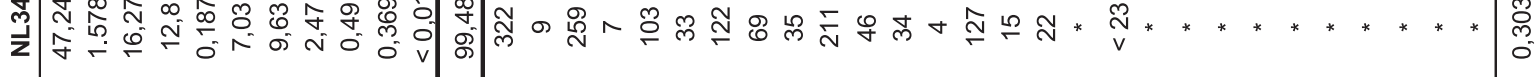

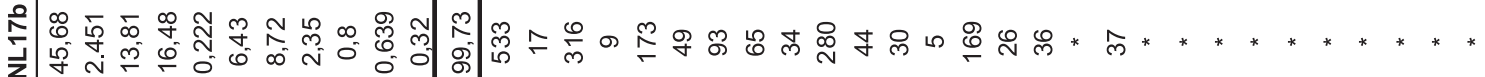

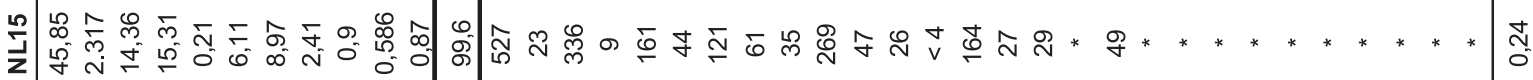

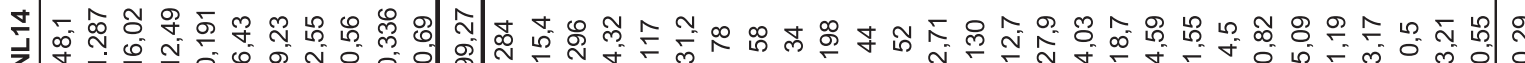

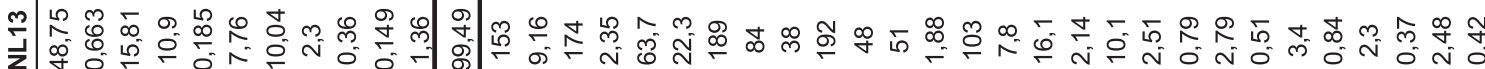

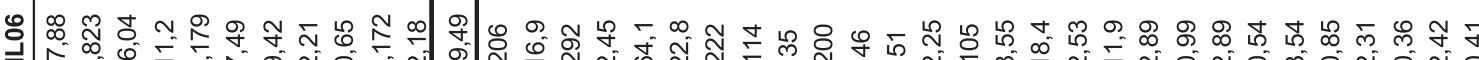

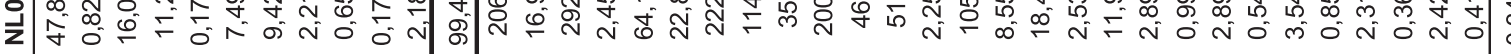

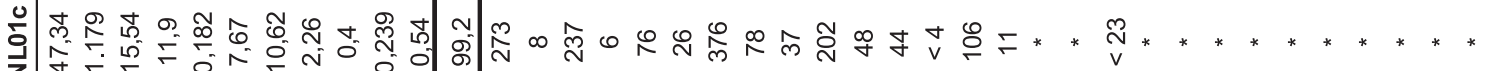

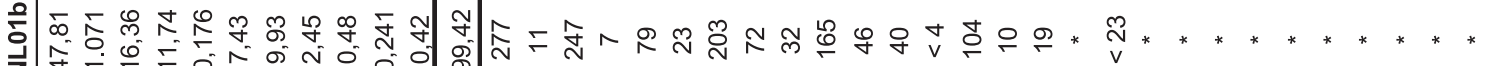

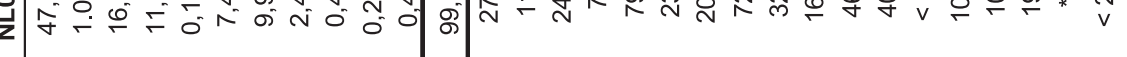

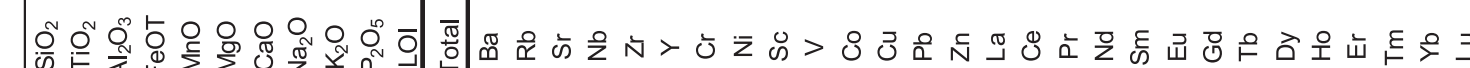
安 1 


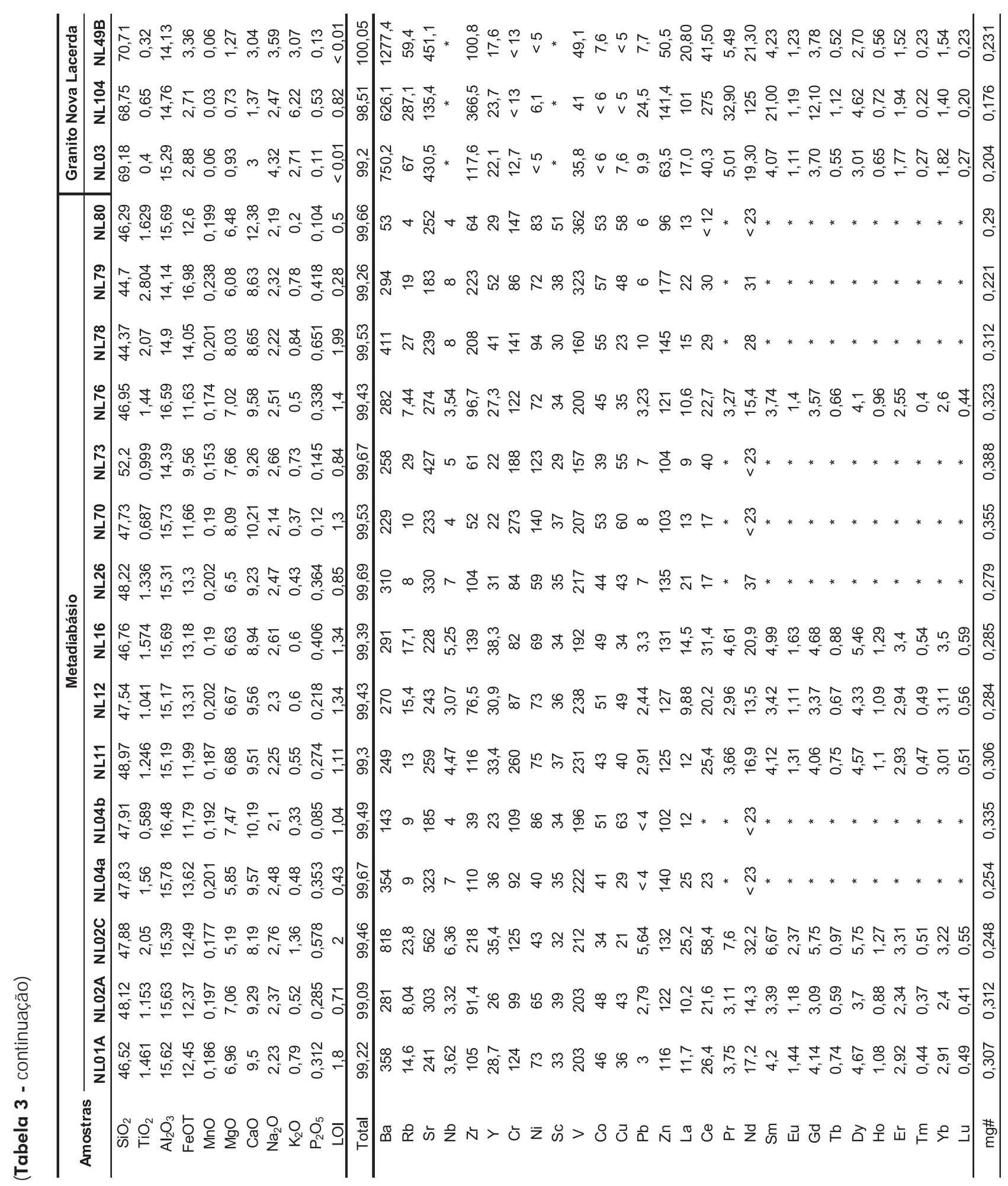


$\mathrm{Cr}$ e Ni diminui. $\mathrm{CaO}$ não exibe variação significativa. Observam-se ainda nos diagramas das Figuras 7 e 8 que os litotipos diabásios e metadiabásios não se separam em grupos geoquímicos distintos. Este comportamento sugere que tais rochas apresentam mesma tendência evolutiva.

\section{ASPECTOS PETROGENÉTICOS}

O estudo petrogenético das rochas basálticas deve tratar de sua origem e evolução. A origem pressupõe a investigação da fonte mantélica e a evolução dos mecanismos petrogenéticos responsáveis pela formação dessas rochas.

As razões entre elementos incompatíveis têm sido usadas para a identificação da fonte parental, pois são muito pouco sensíveis durante fusões mantélicas cujas porcentagens são aproximadamente mantidas, e não variam durante a cristalização fracionada. $\mathrm{O}$ índice $\mathrm{Zr}$ vs. elementos incompatíveis têm demonstrado ser uma boa ferramenta para esse estudo (e.g., Bellieni et al., 1995, entre outros). A Figura 9 mostra a variação dessas razões para diabásios e metadiabásios. A razão $\mathrm{Zr} / \mathrm{Y}$ nos diabásios varia entre 2,74 e 4,36, $\mathrm{Zr} / \mathrm{Nb}(11,29$ - 33,76), Zr/Ba $(0,25$ - 0,78), Zr/Ti $(0,01$ $0,02)$. Nos metadiabásios $\mathrm{Zr} / \mathrm{Y}$ varia entre 1,7 e $5,8, \mathrm{Zr} / \mathrm{Nb}$ (9,75 - 34,28), Zr/Ba (0,23 - 1,21), Zr/Ti (0,01 - 0,02). Os diagramas da Figura 9 mostram razoável variação entre os valores máximos e mínimos das diversas razões, sugerindo que diferentes magmas toleíticos formaram-se a partir de fonte mantélica heterogênea, uma vez que os valores já citados de ${ }^{87} \mathrm{Sr}{ }^{86} \mathrm{Sr}$ (Tabela 2) não favorecem contaminação crustal, consideração porém meramente indicativa, que deverá ser constatada por novos dados isotópicos ora em andamento. De qualquer modo as razões entre elementos incompatíveis de diabásios e metadiabásios exibem intervalos de variação semelhantes, o que permite presumir que ambos os litotipos foram originados pela mesma fonte magmática.

Um dos processos teoricamente possíveis para a formação dos diques de diabásio e metadiabásio é a cristalização fracionada. Este mecanismo de diferenciação foi avaliado quantitativamente por cálculos de balanço de massa, utilizando o Programa Genesis (Teixeira, 1997). O ajuste para elementos maiores no processo de cristalização fracionada é aceito quando a somatória dos quadrados dos resíduos ( $\left(\mathrm{res}^{2}\right.$ ) são inferiores a 0,5 (ajuste bom) e 0,2 (ajuste ótimo; Pinese, 1997). Para os elementos traços utilizou-se a lei de fracionamento de Rayleigh, controlada pela seguinte equação: $C_{L}=C_{O} \cdot F^{(D-1)}$, onde $C_{L}$ é a concentração do elemento traço no líquido residual, $\mathrm{C}_{\mathrm{O}}$ é a concentração do elemento traço no líquido inicial, D é o coeficiente de distribuição global do elemento e F é a fração líquida restante após o fracionamento.

O resultado dos testes em elementos traços foi avaliado comparando as concentrações calculadas divididas pe- las concentrações observadas (calc./obs.). Os percentuais dos erros relativos aos elementos traços são considerados: razoável com $30 \%$, bom com $20 \%$ e ótimo com $10 \%$ (e.g., Iacumin et al., 2001; Pinese, 1997). Os coeficientes de partição sólido/líquido foram extraídos de Iacumin et al. (2001) e Bossi et al. (1993).

Os resultados obtidos pelos cálculos de balanço de massa indicaram claramente que a variação geoquímica observada entre os diques de diabásio e metadiabásio pode ser explicada por cristalização fracionada. A sequência para a cristalização fracionada é descrita pela diferenciação do dique de diabásio com índice de diferenciação mg\# igual a 0,36 (amostra NL13), para o dique de metadiabásio com mg\# igual a 0,31 (amostra NL2A). Esta diferenciação é compatível com $31 \%$ de fracionamento de olivina (1\%), augita (13\%), plagioclásio (16\%) e anfibólio (1\%). Em geral, os valores de elementos traços (calculados/observados) indicam, na maioria, percentuais ótimos, com exceção de $\mathrm{Yb}$ e Lu (Tabela 4). Nesta sequência fica evidente que diabásios e metadiabásios podem ser gerados a partir do mesmos magmas através de cristalização fracionada.

A Figura 10 apresenta diagramas multielementares de amostras selecionadas dos diques de diabásios e metadiabásios, normalizados segundo o manto primitivo de McDonough e Sun (1995). Nestas figuras observa-se que os diques estudados mostram variações do enriquecimento contínuo sem separação em grupos com altos e baixos teores de elementos traços, o que é condizente com inferências obtidas através de relação entre incompatíveis e cristalização fracionada indicando que ambas as litologias provém do mesmo magma. A forte anomalia negativa de $\mathrm{Nb}$ é comum aos diabásios e metadiabásios, e os padrões de distribuição dos elementos incompatíveis nas diversas amostras são homogêneos. Quando comparados aos clássicos padrões OIB, E-MORB e N-MORB, diabásios e metadiabásios situam-se entre OIB e E-MORB, sendo em média próximos destes. Existem, porém, fortes diferenças entre esses padrões e as amostras estudadas, em razão da presença de anomalias positivas de $\mathrm{Rb}$, $\mathrm{K}$ e principalmente $\mathrm{Ba}$, e de pronunciadas anomalias negativas de $\mathrm{Nb}$. Essas feições caracterizam basaltos de arcos de ilhas e intracontinentais, distinguindo-os dos existentes em ilhas oceânicas e cadeias meso-oceânicas (cf. Brenan et al., 1994), e podem ser explicadas ou por contaminação crustal ocorrida ainda na câmara magmática, ou durante a ascensão do magma na crosta; ou por fonte mantélica previamente contaminada. Mecanismo largamente aceito na literatura (cf. Ayers, 1998; Brenan et al., 1994) atribui a contaminação mantélica à subdução de crosta oceânica sob o manto litosférico. O enriquecimento em terras raras leves (LREE) e elementos litófilos de grande raio iônico (LILE) é atribuído a sedimen- 

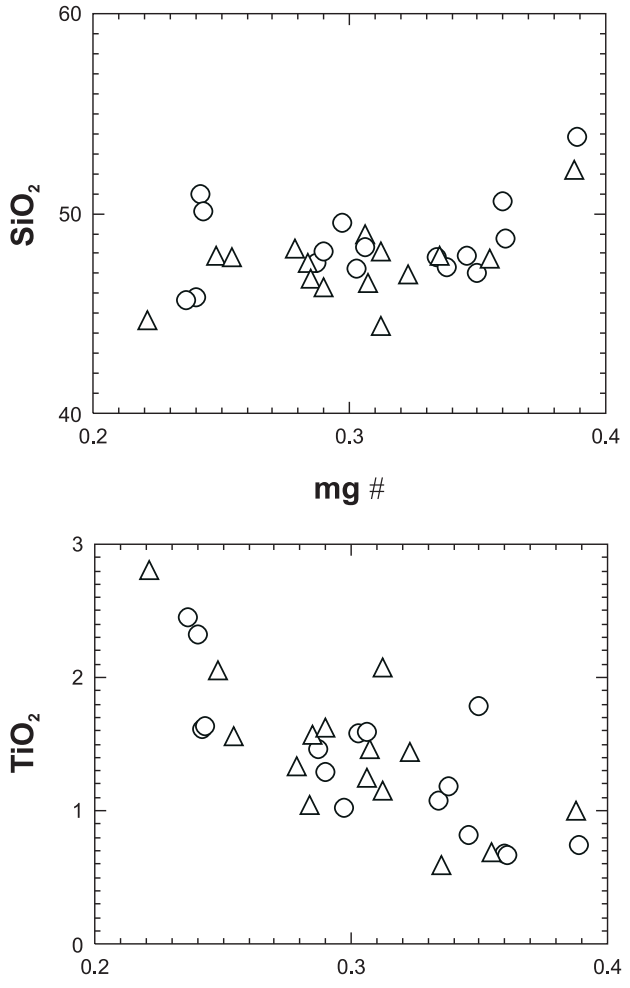

mg \#

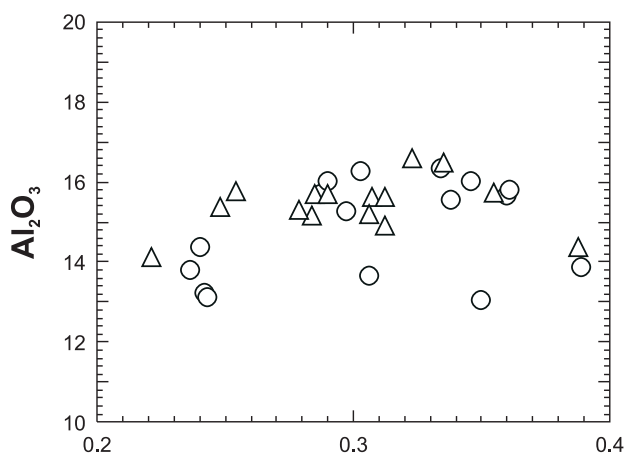

mg \#

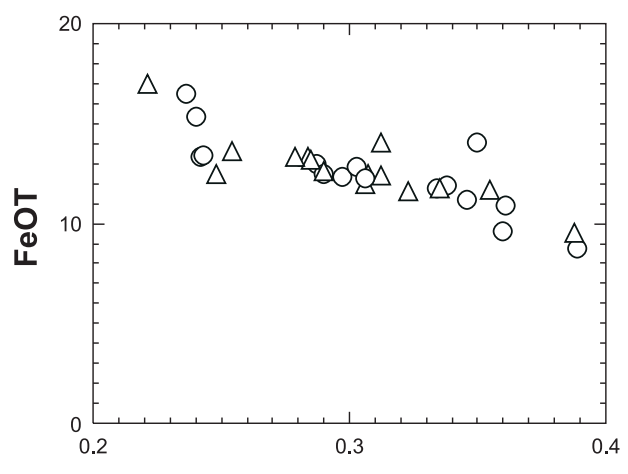

mg \#

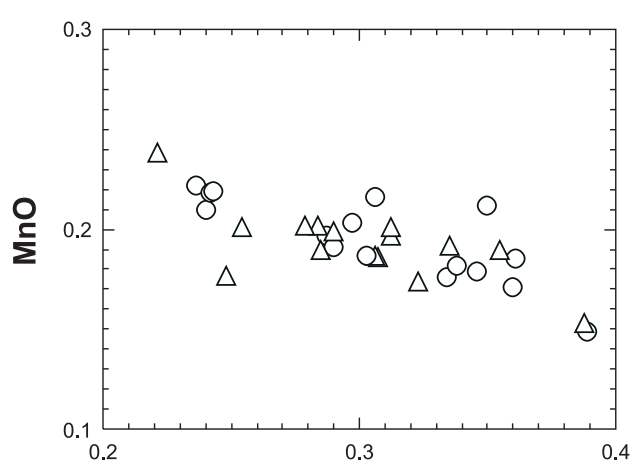

mg \#

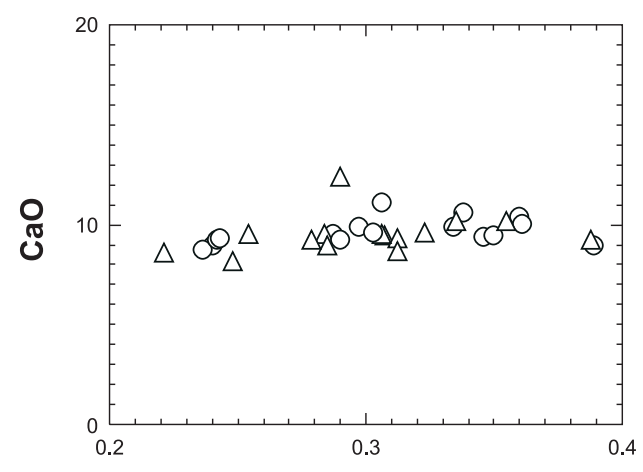

mg \#

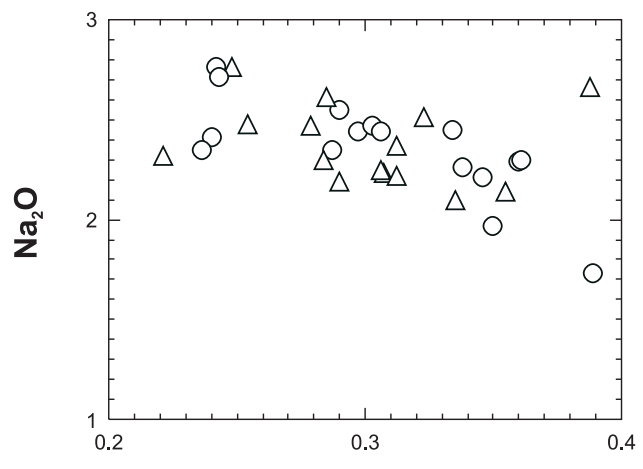

mg \#

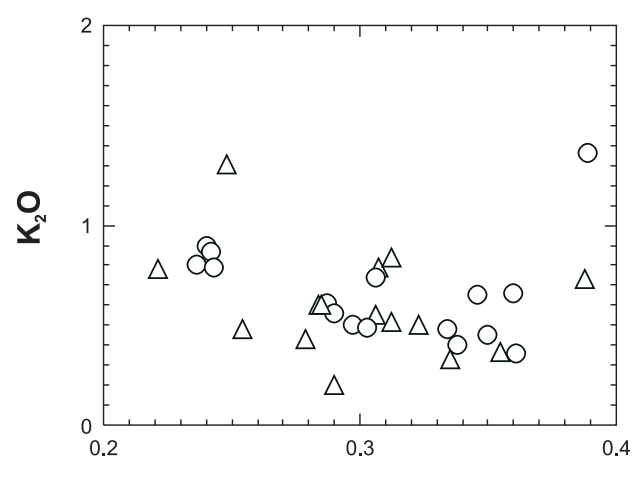

mg \#

Figura 7. Diagramas de variação (mg\# vs. óxidos) dos litotipos máficos. Símbolos como na Figura 5. 

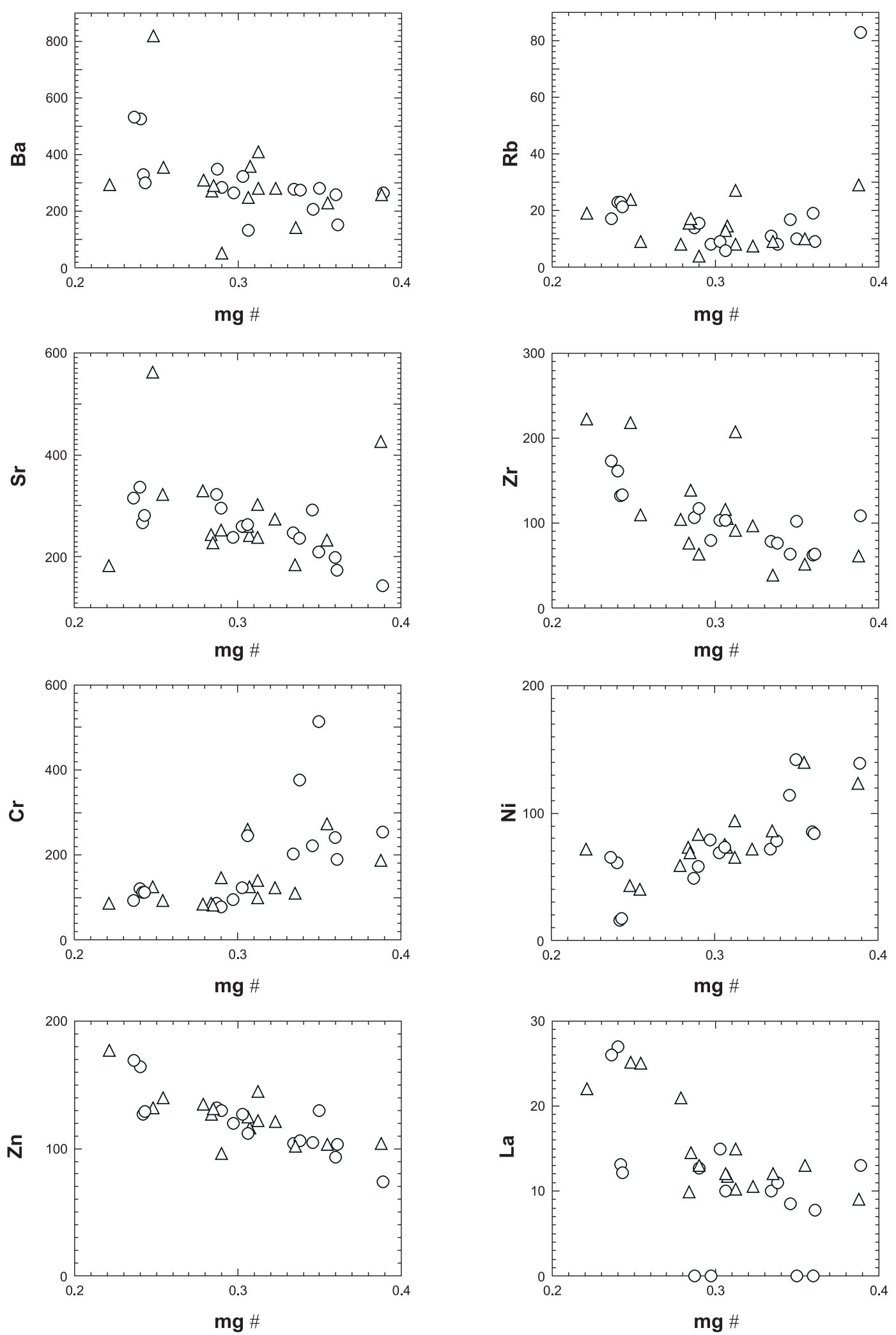

Figura 8. Diagramas de variação (mg\# vs. elementos traços) dos litotipos máficos. Símbolos como na Figura 5. 

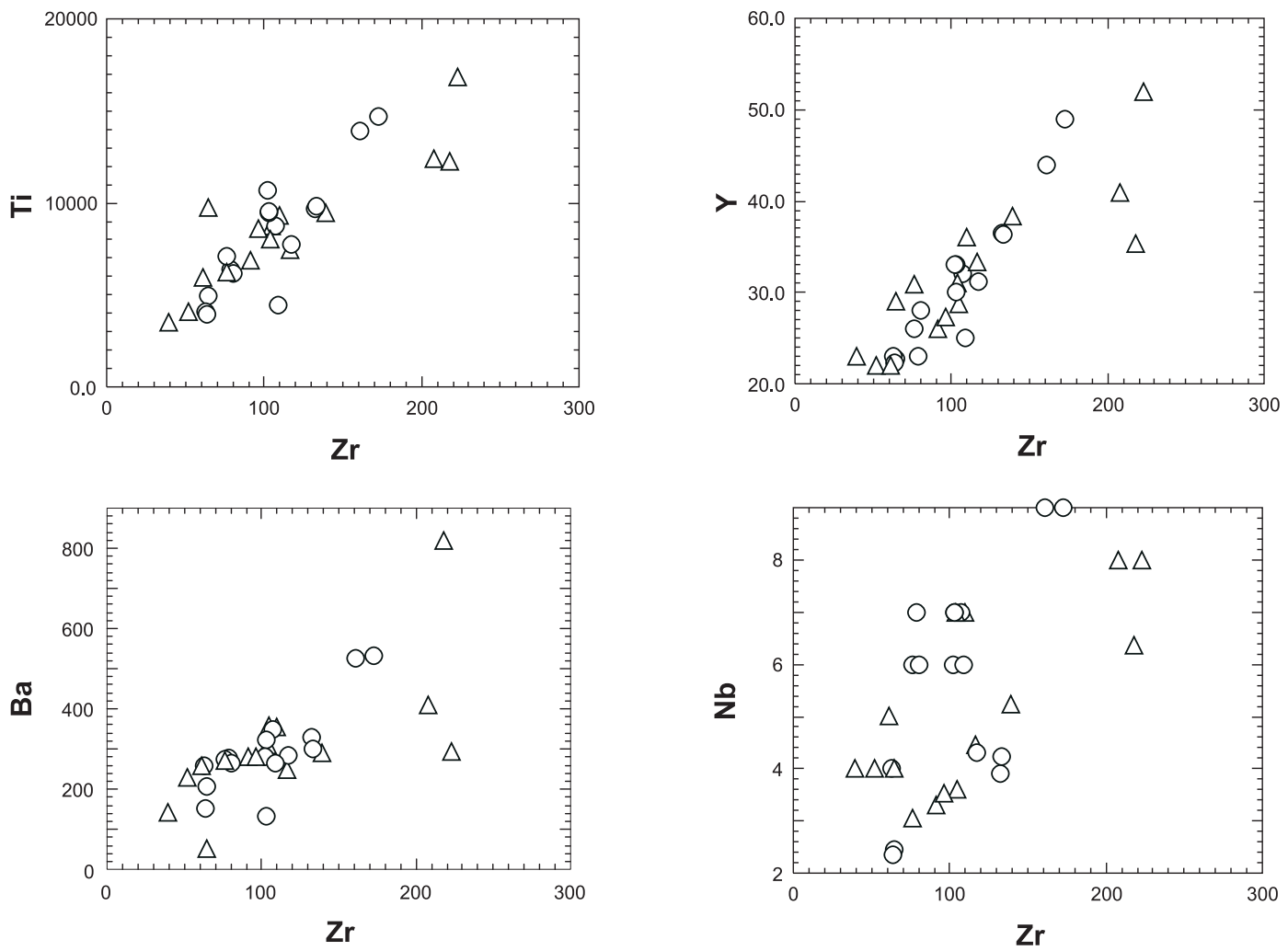

Figura 9. Diagramas de correlação entre Zr vs. elementos traços dos litotipos máficos-ultramáficos. Símbolos como na Figura 5.

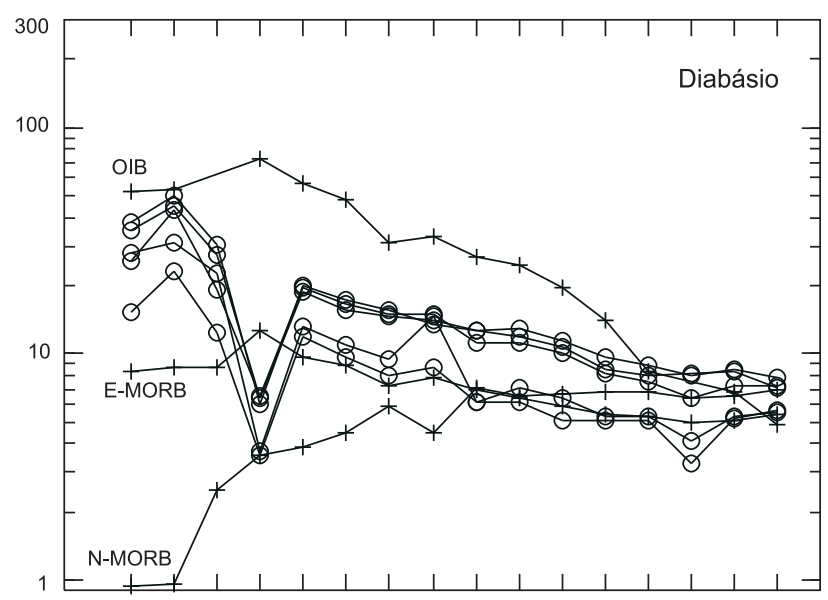

$\mathrm{Rb} \quad \mathrm{Ba} \mathrm{K} \quad \mathrm{Nb}$ La $\mathrm{Ce} \mathrm{Nd} \mathrm{Sr} \quad \mathrm{Zr} \mathrm{Sm} \mathrm{Eu}$ Gd Dy $\mathrm{Ti} \quad \mathrm{Y} \quad \mathrm{Yb}$

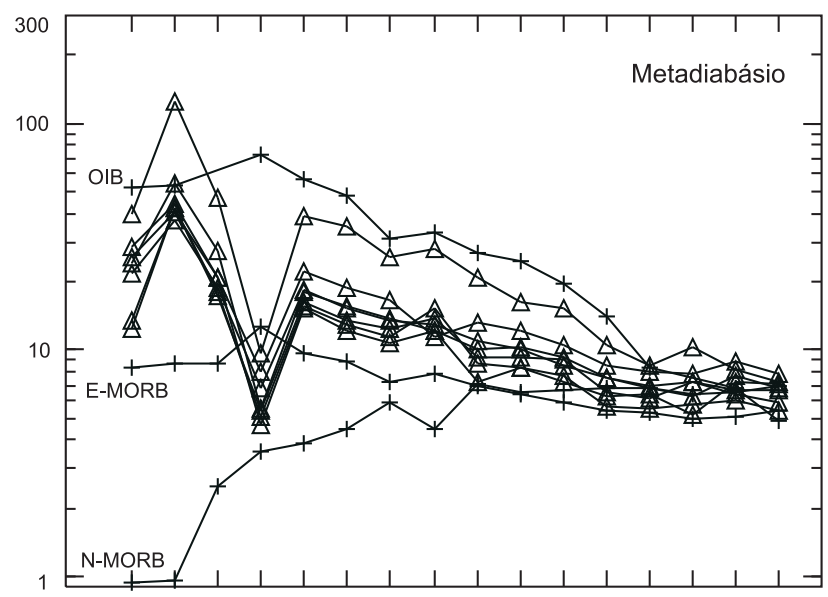

$\mathrm{Rb} \quad \mathrm{Ba} \mathrm{K}$ Nb La Ce $\mathrm{Nd} \mathrm{Sr} \mathrm{Zr} \mathrm{Sm}$ Eu Gd Dy $\mathrm{Ti} \quad \mathrm{Y}$ Yb

Figura 10. Diagrama de multi-elementos, normalizados para o manto primitivo segundo os valores de McDonough e Sun (1995). O s padrões O IB, E-MO RB e N-MO RB (McDonough e Sun, 1995) são apresentados para efeito de comparação. Símbolos como na Figura 5. 
Tabela 4. Cálculo de balanço de massa por cristalização fracionada. Ol. O livina. Aug. Augita. Pla. Plagioclásio. Anf. Anfibólio. Calc. Valores calculados. Obs. Valores observados da análise. $\sum$ res $^{2}$. Somatória dos quadrados dos resíduos dos elementos maiores. SR. Porcentagem de fração sólida removida.

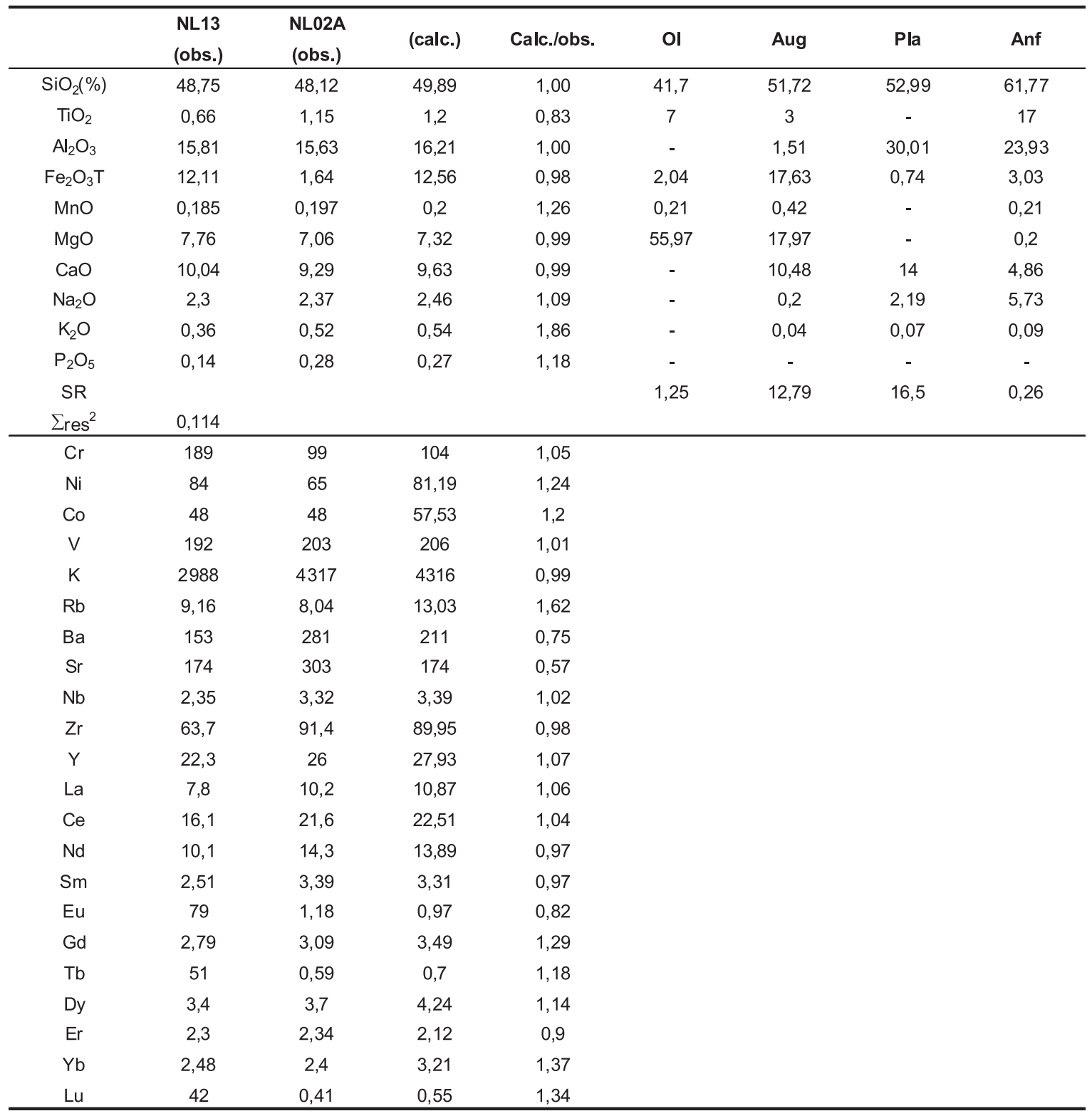

tos da parte superior da crosta (Weaver, 1991) enquanto as anomalias negativas de $\mathrm{Nb}$ e Ta relacionam-se à retenção de rutilo por eclogitos da crosta oceânica (Cordery et al., 1997; Takahashi et al., 1998; Ayers, 1998; Rivalenti et al., 1998; Leitch e Davis, 2001). Pequenas quantidades de rutilo $(\sim 2 \%)$ são suficientes para evitar o enriquecimento desses elementos no manto (Brenan et al., 1994). Embora as razões iniciais ${ }^{87} \mathrm{Sr} /{ }^{86} \mathrm{Sr}$ não favoreçam contaminação crustal, é necessário estudo isotópico mais acurado para decidir-se a questão.

\section{CONSIDERAÇÕES FINAIS}

Os diques toleíticos da região de Nova Lacerda e Conquista D’Oeste, no Domínio Jauru pertencem à província tectônica Rondoniana-San Ignácio. As características geoquímicas e a idade desse enxame (1380 \pm 32 Ma) assemelham-se às exibidas pelas intrusões máficas do Complexo Colorado, em Rondônia (1,35 - 1,36 Ga) (Teixeira et al., 2006; Girardi et al., 2005). As características geológicas, geoquímicas e isotópicas dos toleítos do Complexo Colo- 
rado permitiram atribuir sua origem a ambiente de arco de ilhas, decorrente das subducção de crosta oceânica sob o manto (Girardi et al., 2008). Os dados geoquímicos disponíveis para os toleítos estudados no presente trabalho são compatíveis com ambiente intracontinental ou de arco de ilhas. A conjugação de dados isotópicos desses diques e de suas rochas encaixantes, ora em andamento, os dados geoquímicos e petrológicos destas e os estudos referentes à origem do material contaminante serão utilizados para o definição do provável ambiente tectônico.

A somatória dos dados aqui apresentados, e as inferências a serem obtidas com essas novas informações, permitirão avançar no conhecimento dos toleítos da região de Nova Lacerda e Conquista D’Oeste, contribuindo-se dessa forma para a evolução do estudo geotectônico da província Rondoniana-San Ignácio.

\section{AGRADECIMENTOS}

Os autores gostariam de prestar seus agradecimentos à FAPESP (07/58762-2), à FAPEMAT e ao CNPq, pelo suporte financeiro. A geóloga Marília Bueno Felipe pela ajuda e realização do Trabalho de Conclusão de Curso e aos laboratórios do GMG/IGc/USP pela realização das análises geoquímicas e geocronológicas.

\section{REFERÊNCIAS BIBLIOGRÁFICAS}

AYERS, J. Trace element modeling of aqueous fluidperidotite interaction in the mantle wedge of subduction zones. Contributions to Mineralogy and Petrology, v. 132, p. 390-404, 1998.

BASTOS LEAL, L. R.; TEIXEIRA, W.; PICCIRILO, E. M.; MENEZES LEAL, A. B.; GIRARDI, V. A. V. Geocronologia $\mathrm{Rb} / \mathrm{Sr}$ e $\mathrm{K} / \mathrm{Ar}$ do enxame de diques máficos de Uauá, Bahia (Brasil). Geochimica Brasilienses, v. 8, n. 1, p. 99-114, 1994.

BELLIENI, G.; PETRINI, R.; PICCIRILLO, E. M.; CAVAZZINI, G.; CIVETTA, L.; COMIN CHIARAMONTI, P.; MELFI, A. J.; BERTOLO, S.; DE MIN, A. Proterozoic mafic dyke swarms of the Sao Francisco Craton (SE-Bahia State, Brasil): petrology and $\mathrm{Sr}-\mathrm{Nd}$ isotopes. European Journal of Mineralogy, v. 3, p. 429-449, 1991.

BELLIENI, G.; PICCIRILLO, E. M.; PETRINI, R.; GIRARDI, V. A. V.; MENEZES LEAL, A. B.; TEIXEIRA, W.; BASTOS LEAL, L. R.; DE MIN, A.;COMIN CHIARAMONTI, P.;TANNER DE OLIVEIRA, M. A. F. Petrological and Sr-Nd evidence bearing on early on early proterozoic magmatic events of the subcontinental mantle:
São Francisco Craton (Uauá, NE-Brazil). Contributions to Mineralogy and Petrology, v. 122, p. 252-261, 1995.

BELLIENI, G.; PETRINI, R.; PICCIRILLO, E. M.; BRITO, C. M.; FIGUEIREDO, A. M. G.; MARQUES, L. S.; DE MIN, A.; MELFI, A. J. Petrogenesis and tectonic significance of the late proterozoic unmetamorphosed mafic dyke swarms from the Salvador area (NE Brazil). Neues Jahrbuch Mineralogie Abhandlungen, v. 173, n. 3, p. 327-350, 1998.

BESWICK, A. E. Some geochemical aspects of alteration and genetic relations in komatiitic suites. In: ARDNT, N. T.; NESBITT, E. G. Komatiites. London: George Allen and Unwin, 1982. p. 283-308.

BOSSI, J.; CAMPAL, N.; CIVETA, L.; DEMARCHI, G.; GIRARDI, V. A. V.; MAZZUCCHELLI, M.; NEGRINI, L.; RIVALENTI, G.; FRAGOSO CÉSAR, A. R. S.; SINIGOI, S.; TEIXEIRA, W.; PICCIRILLO, E. M.; MOLESINI, M. 1993. Early proterozoic dike swarms from western Uruguay: geochemistry, $\mathrm{Sr}-\mathrm{Nd}$ isotopes and petrogenesis. Chemical Geology, v. 106, p. 263-277, 1993.

BRENAN, J. M.; SHAW, H. F.; PHINNEY, D. L.; RYERSON, F. J. Rutile-aqueous partitioning of Nb, Ta, Hf, $\mathrm{Zr}$, U and Th: implications for high field strength element depletions in island-arc basalts: Earth and Planetary Science Letters, v. 128, p. 327-339, 1994.

CORDANI, U. G.; TEIXEIRA, W. Proterozoic accretionary belts in the Amazonian Craton. In: HATCHER Jr., R. D.; CARLSON, M. P.; MCBRIDE, J. H.; MARTINEZ CATALÁN, J. R.. (Org). The 4D framework of continental crust: GSA Memoir, Boulder, Colorado. Geological Society of America Book Editors, 2007. v. 200. p. 297-320.

CORDERY, M. C.; DAVIES, J. F.; CAMPBELL, I. H. Genesis of flood basalts from eclogite-bearing mantle plumes: Journal of Geophysical Research, v. 102, p. 20179-20198, 1997.

CORRÊA da COSTA, P. C.; GIRARDI, V. A. V. Petrografia e química mineral dos diques máficos da região Crixás-Goiás, Estado de Goiás. Geologia USP - Série Científica, v. 4, n. 2, p. 27-42, 2004.

CORRÊA da COSTA, P. C.; GIRARDI, V. A. V. Petrology, geochemistry and Sr-Nd isotopes of the paleoproterozoic dikes from the Goiás - Crixás Archean Block, Goiás State, Brazil. Revista Brasileira de Geociências, v. 35, n. 1, p. 135-150, 2005. 
CORRÊA da COSTA, P. C.; RUIZ, A. S.; MATOS, J. B.; GIRARDI, V. A. V.; ALMEIDA, H. L. Estudo Geoquímico dos diques máficos da região de Nova Lacerda (MT). Porção sudoeste do Cráton Amazônico. In: CONGRESSO BRASILEIRO DE GEOQUÍMICA, 10.; SIMPÓSIO DE GEOQUÍMICA DOS PAIISES DO MERCOSUL, 11, 2005, Porto de Galinhas. Resumos Expandidos... Porto de Galinhas, 2005.

CORRÊA da COSTA, P. C.; CARNEIRO, A. C.; TEIXEIRA, W.; GIRARDI, V.; NALINI JÚNIO, H. A.; OLIVEIRA, A. H.; FERNANDES, R. A. Estudo geoquímico e petrológico dos diques máficos da região de Cadeias-Campo Belo-Santo Antônio do Amparo (MG), porção meridional do Cráton São Fransisco. Geologia USP. Série Científica, v. 5, p. 65-84, 2006.

CORRÊA da COSTA, P. C.; GIRARDI, V. A. V.; TEIXEIRA, W. 40Ar/39Ar geochronology of the GoiásCrixás dyke swarm, Central Brazil: further evidence of the neoarchean-paleoproterozoic tectonic boundary in South America and Nd-Sr signature of the subcontinental mantle throughout time. International Geology Review, v. 48, p. 547-560, 2006a.

COX, K. G.; BELL, J. D.; PUNKHURST, R. J. The interpretation of igneous rocks. London: George Allen \& Unwin Publishers, 1979. 450 p.

D'AGRELLA FILHO, S.; PACCA, I. I. G.; TRINDADE, R. I. F.; TEIXEIRA, W.; RAPOSO, M. I. B.; ONSTOTT, T. C. Paleomagnetism and ${ }^{40} \mathrm{Ar} /{ }^{39} \mathrm{Ar}$ ages of mafic dikes from Salvador (Brazil): new constraints on the São Francisco Craton APW path between 1080 and 1010 Ma. Precambrian Research, v. 132, p. 55-77, 2004.

FELIPE, M. B. Estudo geológico e petrográfico região de Nova Lacerda e Conquista D'Oeste SW do Estado de Mato Grosso com enfoque na geoquímica dos diques máficos. 2007. Trabalho de Conclusão de Curso - Universidade Federal de Mato, Cuiabá, 2007.

GERALDES, M. C.; VAN SCHMUS, W. R.; CONDIE, K. C.; BELL, S.; TEIXEIRA, W.; BABINSKI, M. Proterozoic geologic evolution of the SW part of the Amazonian Craton in Mato Grosso state, Brazil. Precambrian Research, v. 111, p. 91-128, 2001.

GIRARDI, V. A. V.; MAZZUCCHELLI, M.; MOLESINI, M.; CIVETTA, L.; PETRINI, R.; BOSSI, J.; CAMPAL, N.; TEIXEIRA, W.; CORREIA, C. T. Petrology and geochemistry of the mafic dyke swarm of the Treinta $Y$
Treis region, Northeast Uruguay. Journal South American. Earth Science, v. 9, p. 243-249, 1996.

GIRARDI, V. A. V.; TEIXEIRA, W.; BETTENCOURT, J. S.; CORREAA da COSTA, P. C.; SATO, K. Características isotópicas $(\mathrm{Nd}, \mathrm{Sr})$ e geoquímicas de rochas intrusivas máficas mesoproterozóicas do Estado da Rondônia, SW do Craton Amazônico: CONGRESSO BRASILEIRO DE GEOQUÍMICA, 10.; SIMPÓSIO DE GEOQUÍMICA DE PAÍSES DO MERCOSUL, 2., Porto de Galinhas, 2005. Resumos Expandidos, Porto de Galinhas, 2005. (CD-ROM).

GIRARDI, V. A. V. Sm-Nd Isotopic study of selected paleo and mesoproterozoic mafic intrusions from cratonic areas of Brazil and Uruguay: inferences on their source mantles. SOUTH AMERICAN SYMPOSIUM ON ISOTOPE GEOLOGY, 5., Montevideu, 2006. Short Papers, Montevideu, 2006. p. 378-381.

GIRARDI, V. A. V.; TEIXEIRA, W.; BETTENCOURT, J. S.; ANDRADE, S.; NAVARRO, M. S.; SATO, K. Trace element geochemistry and Sr-Nd characteristics of mesoproterozoic mafic intrusive rocks from Rondônia, Brazil, SW Amazonian Craton: petrogenetic and tectonic inferences. Episodes, v. 31, n. 4, p. 392-400, 2008.

IACUMIN, M.; DE MIN, A.; PICCIRILLO, E. M.; BELLIENI, G. Source mantle heterogeneity and its role in the genesis of Late archaean-proterozoic (2.7-1.0 Ga) and Mesozoic (200 and $130 \mathrm{Ma}$ ) tholeiitic magmatism in the South American Platform. Earth-Science Reviews, v. 62, p. 365-397, 2003.

IACUMIN, M.; PICCIRILLO, E. M.; GIRARDI, V. A. V.; TEIXEIRA, W.; BELLIENI, G.; ECHEVESTE, H.; FERNANDEZ, R.; PINESE, J. P. P.; RIBOT, A. Early proterozoic calc-alkaline and middle proterozoic tholeiitic dike swarms from Central-Eastern Argentina: petrology, geochemistry, Sr-Nd Isotopes and tectonic implications. Journal of Petrology, v. 42, p. 2109-2143, 2001.

IRVINE, I. N.; BARAGAR, W. R. A. A guide to the chemical classification of the common volcanic rocks. Canadian Journal Earth Science, v. 8, p. 523-548, 1971.

JAQUES, A. L.; GREEN, D. H. Anhydrous Melting of Peridotite at $0-15 \mathrm{~Kb}$ Pressure and the Genesis of Tholeiitic Basalts. Contributions to Mineralogy and Petrology, v. 73, p. 287-310, 1980.

JAQUES, A. L.; GREEN, D. H. Determination of liquid 
compositions in high-pressure melting of peridotite. American Mineralogist, v. 64, p. 1312-1321, 1979.

KAWASHITA, K. O método $\mathrm{Rb}$-Sr em rochas sedimentares. Aplicação para as bacias do Paraná e Amazonas. 1972. 111 f. Tese (Doutorado) - Instituto de Geociências, Universidade de São Paulo, São Paulo, 1972.

LEITCH, A. M.; DAVIS, G. F. Mantle plumes and flood basalts: enhanced melting from plume ascent and an eclogite component: Journal of Geophysical Research, v. 106, p. 2047-2059, 2001.

LUDWIG, K. R. Isoplot/Ex version 2.10 (A geochronological toolkit for microsoft excel). Barkeley Geochronology Center, 1999. (Special Pubicartion).

MAZZUCCHELLI, M.; RIVALENTI, G.; PICCIRILLO, E.; GIRARDI, V. A. V.; CIVETTA, L. Petrology of the proterozoic mafic dyke swarms of Uruguay and constraints on their mantle source composition. Precambrian Research, v. 74, p. 177-194, 1995.

MAZZUCCHELLI, M.; RIVALENTI, MENEZES LEAL, A. B.; GIRARDI, V. A. V.; BRITO NEVES, B. B.; TEIXEIRA, W. Petrology of metabasaltic dykes in the Diamantina region, Minas Gerais, Brazil. Peiodico di Mineralogia, v. 70, p. 231-254, 2001.

MCDONOUGH, W. F.; SUN, S. S. The composition of the earth. Chemical Geology, v. 120, p. 223-253, 1995.

MENEZES LEAL, A. B.; BELLIENI, G.; GIRARDI, V. A. V.; BASTOS LEAL, L. R.; TEIXEIRA, W.; PICCIRILLO, E. M. Contribuição ao estudo petrológico e geoquímico dos enxames de diques máficos de Uauá, Bahia, Brasil. Geochimica Brasiliensis, v. 9, p. 61-90, 1995.

MENEZES LEAL, A. B.; GIRARDI, V. A. V.; BASTOS LEAL, L. R. Geologia, petrografia e geoquímica dos sills Cotingo e Pedra Preta, Estado de Roraima, Brasil. Geochimica Brasiliensis, v. 20, n. 3, p. 233-250, 2006.

MORAES BRITO, C.; BELLIENI, G.; COMIN-CHIARAMONTI, P.; MELFI, A. J.; PICCIRILLO, E.; TANNER DE OLIVEIRA, M. A. F. Mafic dikes of Salvador (State of Bahia, Brazil): geological and petrological characteristics. Boletim IG-USP-Série Científica, Universidade de São Paulo, v. 20, p. 9-14, 1989.

MORI, P. E.; REEVES, S.; CORREIA, C. T.; HAUKKA, M. Development of a fused glass disc XRF facility and comparison with the pressed powder pellet technique at Instituto de Geociências, University of São Paulo. Revista Brasileira de Geociências, v. 29, p. 441-446, 1999.

NAVARRO, M. S.; ANDRADE, S.; ULBRICH, H. H. G. J.; GOMES, C. B.; GIRARDI, V. A. V. The analysis of rare earth elements with ICP-MS in basaltic and related rocks: testing the efficiency of sample decomposition procedures. Geostandards and Geoanalytical Research, v. 32, n. 2, p. 167-180, 2008.

PEARCE, T. H. A contribution to the theory of variations diagrams. Contributions Mineralogy and Petrology, v. 19, p. 42-57, 1968.

PINESE, J. P. P. Geoquímica, geologia isotópica e aspectos petrológicos dos diques máficos pré-cambrianos da região de Lavras (MG), porção sul do Cráton São Francisco. 1997. 178 f. Tese (Doutorado) - Instituto de Geociências, Universidade de São Paulo, São Paulo, 1997.

RIVALENTI G.; MAZZUCCHELLI, M.; MOLESINI, M.; PETRINI, R.; GIRARDI, V. A. V.; BOSSI, J.; CAMPAL, N. Petrology of late proterozoic mafic dikes in the Nico Perez region, Central Uruguay. Mineraogy and Petrology, v. 55, p. 239-263, 1995.

RIVALENTI, G.; MAZZUCCHELLI, M.; GIRARDI, V. A. V.; CAVAZZINI, G.; FINATTI, C.; BARBIERI, M. A.; TEIXEIRA, W. Petrogenessis of the paleoproterozoic basalt-andesit-rhyolite dyke association in the Carajás region. Amazonian Craton. Lithos, v. 43, p. 235-265, 1998.

RUIZ, A. S. Evolução geológica do sudoeste do Cráton Amazônico região limítrofe Brasil-Bolívia - Mato Grosso. 2005. 260 f. Tese (Doutorado), Universidade Estadual Paulista, Rio Claro, 2005.

RUIZ, A. S.; SIMÕES, L. S. A.; CORRÊA DA COSTA, P. C.; MATOS, J. B.; RUIZ, L. M. B. A.; GODOY, A. M.; SOUZA, M. Z. A. Enxame de diques máficos (Suíte Intrusiva Rancho de Prata) no SW do Cráton Amazônico: indícios de colapso extensional no Orogeno Sunsás? In: SIMPÓSIO DE VULCANISMO E AMBIENTES ASSOCIADOS, 3., 2005, Cabo Frio. Resumo Expandido... Cabo Frio, 2005.

SAES, G. S. Evolução tectônica e paleogeográfica do aulacógeno Aguapeí (1.2-1.0 Ga) e dos terrenos do seu embasamento na porção sul do Cráton Amazônico. 1999. 135 f. Tese (Doutoramento) - Instuto de Geociências, Universidade de são Paulo, São Paulo, 1999. 
SATO, K.; TASSINARI, C. C. G.; KAWASHITA, K.; PETRONILHO, L. O método geocronológico Sm-Nd no IG/USP e suas aplicações. Anais da Academia Brasileira de Ciências, v. 67, p. 313-336,1995.

STEIGER, R. H.; JAEGER, C. Subcomission on geochronology: convention of the use of decay constants in geochronology and cosmochronology. Contributions to the geologic time scale. Studies in Geology, v. 6, p. 67-72, 1978.

TAKAHASHI, E.; KUSHIRO, I. Melting of dry peridotite at high pressures and basalt magma gênesis. American Mineralogist, v. 68, p. 81-94, 1983.

TAKAHASHI, E.; NAKAJIMA, K.; WRIGHT, T. L. Origin of the Columbia River basalts: melting model of a heterogeneous plume head: Earth and Planetary Science Letters, v. 162, p. 63-80, 1998.

TASSINARI, C. C. G.; MACAMBIRA, M. J. B. Geochronological provinces of the Amazonian Craton. Episodes. v. 22, n. 3, p. 174-182, 1999.

TASSINARI, C. C. G.; BETTENCOURT, J. S.; GERALDES, M. C.; MACAMBIRA, M. J. B., LAFON, J. M. The Amazon Craton. In: CORDANI, U. G.; MILIANI, E. J.; THOMAZ-FILHO, A.; CAMPOS, D.A. (Ed.) Tectonic evolution of South America. In: 31st INTERNATIONAL GEOLOGICAL CONGRESS, 31., 2000, Rio de Janeiro, 2000. p. 41-95.

TASSINARI, C. G. C.; MACAMBIRA, M. J. B. A evolução tectônica do Cráton Amazônico. In: NETO-MANTESSO, V.; BARTORELLI, A.; CARNEIRO, C. D. R.; BRITO-NEVES, B. B. de B. (Org.) Geologia do continente sul-americano: evolução da obra de Fernando Flávio Marques de Almeida. São Paulo: Beca, 2004. p. 471-486.

TEIXEIRA L. R. Genesis versão 2.0. Aplicativo de modelamento geoquímico. [Salvador]: UFBa, 1997. (Curso de Pós-graduação).

TEIXEIRA, W; TASSINARI, C. C. G.; CORDANI, U. G.; KAWASHITA, K. A review of the geochronology of the Amazonian Craton: tectonic implications. Precambrian Research, v. 42, p. 213-227, 1989.

TEIXEIRA, W.; RENNE, P. R.; BOSSI, J.; CAMPAL, N.; D'AGRELLA FILHO, M. S. ${ }^{40} \mathrm{Ar}-{ }^{39} \mathrm{Ar}$ and Rb-Sr geochronology of the Uruguayan dike swarm, Rio de la Plata Craton and implications for proterozoic intraplate acti- vity in western Gondwana. Precambrian Research., v. 93, p. 153-180, 1999.

TEIXEIRA, W.; BETTENCOURT, J. S.; GIRARDI, V. A. V.; ONOE, A.; SATO, K. Mesoproterozoic mantle heterogeneity in the SW Amazonian Craton: 40Ar/39Ar and $\mathrm{Nd}$-Sr isotopic evidence from mafic-felsic rocks. Hanski, Mertanen, Rämo and Vuollo (Ed.) Dyke Swarms - time markers of crustal evolution. London: Taylor \& Francis Group, 2006. p. 113-129.

WEAVER, B. L. The origin of ocean island basalt endmember compositions: trace element and isotopic constraints. Earth and Planetary Science Letters, v. 104, p. $381-397,1991$. 